\title{
Reelin-Nrp1 Interaction Regulates Neocortical Dendrite Development in a Context-Specific Manner
}

\author{
[DTakao Kohno, ${ }^{1}$ Keisuke Ishii, ${ }^{1}$ Yuki Hirota, ${ }^{2}$ Takao Honda, ${ }^{2}$ Makoto Makino, ${ }^{1}$ Takahiko Kawasaki, ${ }^{3}$ \\ (Dazunori Nakajima, ${ }^{2}$ and ${ }^{(D)}$ Mitsuharu Hattori ${ }^{1}$ \\ ${ }^{1}$ Department of Biomedical Science, Graduate School of Pharmaceutical Sciences, Nagoya City University, Nagoya, Aichi 467-8603, Japan, \\ ${ }^{2}$ Department of Anatomy, Keio University School of Medicine, Tokyo, 160-8582, Japan, and ${ }^{3}$ Brain Function Laboratory, National Institute of \\ Genetics, Mishima, Shizuoka 411-8540, Japan
}

Reelin plays versatile roles in neocortical development. The C-terminal region (CTR) of Reelin is required for the correct formation of the superficial structure of the neocortex; however, the mechanisms by which this position-specific effect occurs remain largely unknown. In this study, we demonstrate that Reelin with an intact CTR binds to neuropilin-1 (Nrp1), a transmembrane protein. Both male and female mice were used. Nrp1 is localized with very-low-density lipoprotein receptor (VLDLR), a canonical Reelin receptor, in the superficial layers of the developing neocortex. It forms a complex with VLDLR, and this interaction is modulated by the alternative splicing of VLDLR. Reelin with an intact CTR binds more strongly to the VLDLR/Nrp1 complex than to VLDLR alone. Knockdown of Nrp1 in neurons leads to the accumulation of Dab1 protein. Since the degradation of Dab1 is induced by Reelin signaling, it is suggested that Nrp1 augments Reelin signaling. The interaction between Reelin and Nrp1 is required for normal dendritic development in superficial-layer neurons. All of these characteristics of Reelin are abrogated by proteolytic processing of the six C-terminal amino acid residues of Reelin $(0.17 \%$ of the whole protein). Therefore, Nrp1 is a coreceptor molecule for Reelin and, together with the proteolytic processing of Reelin, can account for context-specific Reelin function in brain development.

Key words: dendrite; neocortex; neuropilin; proteolysis; radial migration

Significance Statement

Reelin often exhibits a context-dependent function during brain development; however, its underlying mechanism is not well understood. We found that neuropilin-1 (Nrp1) specifically binds to the CTR of Reelin and acts as a coreceptor for very-lowdensity lipoprotein receptor (VLDLR). The Nrp1/VLDLR complex is localized in the superficial layers of the neocortex, and its interaction with Reelin is essential for proper dendritic development in superficial-layer neurons. This study provides the first mechanistic evidence of the context-specific function of Reelin ( $>3400$ residues) regulated by the C-terminal residues and Nrp1, a component of the canonical Reelin receptor complex.

Received June 24, 2020; revised Sep. 14, 2020; accepted Sep. 23, 2020.

Author contributions: T. Kohno, T.H., K.N., and M.H. designed research; T. Kohno, K.I., Y.H., and M.M. performed research; T. Kohno, T.H., and T. Kawasaki contributed unpublished reagents/analytic tools; T. Kohno and K.I. analyzed data; T. Kohno wrote the first draft of the paper; T. Kohno, K.N., and M.H. edited the paper; T. Kohno, K.N., and M.H. wrote the paper.

This work was supported by Grants-in-Aid for Scientific Research JP17K08281 and JP20K07051 to T. Kohno, JP2OK06670 to Y.H., JP18K06508 to T.H., JP16H06482 and JP2OH05688 to K.N., JP17H03985 and JP2OH03384 to M.H., Grant-in-aid for Research in Nagoya City University 1922006 to T. Kohno, Japan Spina Bifida \& Hydrocephalus Research Foundation to Y.H., Takeda Science Foundation, Keio Gijuku Academic Development Funds, and Keio Gijuku Fukuzawa Memorial Fund for the Advancement of Education and Research to K.N. We thank Drs. J. Takagi (Osaka University), K. Mikoshiba (ShanghaiTech University), D. Feldheim (University of California at Santa (ruz), and Y. Hatanaka (Osaka University) for valuable comments; and Drs. C. Cepko (Harvard Medical School), T. Curran (Children's Mercy Hospital Kansas City), J.G. Flanagan (Harvard Medical School), C. Hanashima (Waseda University), T. Iwasato (National Institute of Genetics, Japan), J. Miyazaki (Osaka University), K. Nakayama (Kyoto University), and K. Shirotani (Nagasaki University) for providing plasmids.

The authors declare no competing financial interests.

Correspondence should be addressed to Takao Kohno at tkohno@phar.nagoya-cu.ac.jp or Mitsuharu Hattori at mhattori@phar.nagoya-cu.ac.jp.

https://doi.org/10.1523/JNEUROSCI.1907-20.2020

Copyright $\odot 2020$ the authors

\section{Introduction}

The mammalian neocortex has a highly organized six-layered structure that is distinguished by its morphological and functional features. Abnormality of neocortical formation is a risk factor for neuropsychiatric disorders (Ishii et al., 2016; Wasser and Herz, 2017). Projection neurons in the mouse neocortex are generated in either the ventricular or subventricular zone and migrate radially toward the pial surface (Hirota and Nakajima, 2017). Neurons dynamically change their morphology during migration. In the intermediate zone, neurons temporarily adopt multipolar shapes (Tabata and Nakajima, 2003). They then take a bipolar shape and migrate to the cortical plate (CP) (Noctor et al., 2004; Tabata et al., 2009). Once neurons are close to the marginal zone (MZ), they attach their leading process to the $M Z$ and then move to their final position (Nadarajah et al., 2001; Sekine et al., 2011). The leading process transforms into highly branched apical dendrites (Chai et al., 2015; O’Dell et al., 2015). Regulated by several secreted proteins (Cooper, 2014; Valnegri et 
al., 2015), the morphological development of neurons is important not only for neuronal layer formation but also for neuronal circuit formation. However, the mechanisms that regulate the spatiotemporal events in a migrating neuron remain unclear.

Reelin is a large glycoprotein that plays essential and versatile roles in the formation and the function of the brain (Ishii et al., 2016; Hirota and Nakajima, 2017; Wasser and Herz, 2017). In the developing neocortex, Reelin is mainly secreted from CajalRetzius cells in the MZ and binds to the apolipoprotein E receptor 2 (ApoER2) and the very-low-density lipoprotein receptor (VLDLR), which are expressed by migrating neurons (Santana and Marzolo, 2017; Wasser and Herz, 2017). Reelin is also secreted by other types of cells, which may be relevant in neuronal layer formation (Yoshida et al., 2006; Uchida et al., 2009). Reelin induces the tyrosyl phosphorylation of the intracellular protein Dab1, and phosphorylated Dab1 is quickly degraded via the ubiquitin-proteasome pathway (Arnaud et al., 2003). ReelinDab1 signaling controls multiple events during neocortical formation, suggesting context-dependent regulatory mechanisms (Hirota and Nakajima, 2017). One function of Reelin is to control neuronal polarization and dendritic growth (Niu et al., 2004; Jossin and Goffinet, 2007; Matsuki et al., 2010). Recently, it was demonstrated that Reelin concentrated in the MZ regulates the orientation and branching of apical dendrites in superficial-layer neurons (Chai et al., 2015; O'Dell et al., 2015); however, the molecular mechanism by which Reelin controls dendritic development in the MZ has yet to be elucidated (Chai and Frotscher, 2016).

The efficient induction of Dab1 phosphorylation in cultured neurons requires the C-terminal region (CTR) of Reelin (Nakano et al., 2007). In our previous study with knock-in mice, we demonstrated that the CTR of Reelin is required for the apical dendritic development of superficial-layer neurons (Kohno et al., 2015). Also, we have shown that Reelin is proteolytically cleaved within the CTR (WC cleavage) (Kohno et al., 2015). During WC cleavage, Reelin with intact CTRs (Reelin-FL, 3461 amino acid residues) is converted to Reelin missing the last six amino acid residues (Reelin- $\Delta 6,3455$ amino acid residues) (Kohno et al., 2015). Reelin-FL, but not Reelin- $\Delta 6$, strongly binds to the neuronal cell membrane (Kohno et al., 2015). These results suggested that these six terminal amino acid residues play an important role in the interaction between Reelin-FL and an as yet unidentified molecule and that this interaction is required for the apical dendritic development of superficial-layer neurons.

In this study, we show that Reelin-FL binds to neuropilin-1 (Nrp1) on the neuronal cell membrane. Nrp1 is colocalized with VLDLR in superficial-layer neurons and forms a complex with VLDLR. Reelin-FL strongly binds to the VLDLR/Nrp1 complex. Furthermore, the interaction of Reelin-FL with Nrp1 is required for the proper development of apical dendrites in superficiallayer neurons. This study demonstrates a novel model regarding the context-specific functions of Reelin.

\section{Materials and Methods}

Animals. All experimental protocols used in this study were approved by the Animal Care and Use Committees of Nagoya City University and Keio University and were performed according to the Institutional Guidelines on Animal Experimentation of Nagoya City University and Keio University. The mice were housed under a $12 \mathrm{~h}$ light/dark cycle with lights on between 6:00 A.M. and 6:00 P.M. with standard diets and water ad libitum. Slc:ICR mice were obtained from Japan SLC. For timed mating, noon of the day of vaginal plug detection was designated as E0.5 and the day of birth was designated as P0. Both male and female pups were used for all experiments.

Cell culture and transfection. HEK293T cells, COS-7 cells, and cortical neurons were cultured as previously described (Nakano et al., 2007; Kohno et al., 2015). Transfection was performed using either Lipofectamine 2000 (Thermo Fisher Scientific) or Polyethylenimine "Max" (Polysciences), according to the manufacturer's instructions. To obtain recombinantReelin-containing supernatant, the culture medium was replaced with Opti-MEM (Thermo Fisher Scientific) $5 \mathrm{~h}$ after transfection and was then cultured for $72 \mathrm{~h}$. For nucleofection, cortical neurons $\left(3 \times 10^{6}\right.$ cells/ transfection) were resuspended with $100 \mu \mathrm{l}$ of a supplemented nucleofector solution (VPG-1001, Lonza Walkersville), $50 \mu \mathrm{g}$ of short hairpin RNA (shRNA) plasmid, and $5 \mu \mathrm{g}$ of pCAGGS-EGFP. The suspension was transferred to a cuvette and electroporated using Nucleofector II (Lonza Walkersville). After nucleofection, the cells were transferred into a $2 \mathrm{ml}$ neurobasal medium (Thermo Fisher Scientific) containing 10\% FBS using a plastic pipette. The cell suspension was plated on a $0.01 \%$ poly-L-lysine-coated 12 -well plate $(600 \mu \mathrm{l} /$ well). Two hours after plating, the culture medium was replaced with neurobasal medium supplemented with 2\% B-27 (Thermo Fisher Scientific) and 2 mm Glutamax (Thermo Fisher Scientific).

Antibodies. The antibodies used for Western blotting (WB), immunoprecipitation (IP), immunocytochemistry (ICC), or immunohistochemistry (IHC) were as follows: mouse monoclonal anti-Reelin G10 (MAB5364, Merck Millipore, RRID:AB_2179313; WB 1:2000 and ICC 1:500), mouse monoclonal anti-Reelin E5 (sc-25346, Santa Cruz Biotechnology, RRID:AB_628210; WB 1:1000), rabbit polyclonal anti-GFP (598, MBL, RRID:AB_591819; WB 1:3000, IP 1:1000, IHC 1:1000), rat monoclonal anti-GFP (04404-26, Nacalai Tesque; IHC 1:500), rabbit polyclonal anti-placental alkaline phosphatase (AP, GTX72989, GeneTex, RRID:AB_374630; WB 1:1000), rabbit monoclonal anti-placental AP (ab133602, Abcam; ICC 1:500), rat monoclonal anti-HA 3F10 (11867423001, Roche Diagnostics, RRID:AB 390918; WB $50 \mathrm{ng} / \mathrm{ml})$, mouse monoclonal anti- $\beta$-actin (013-24553, Wako; WB 1:8000), rat monoclonal anti-Dab1 antibody 4E12 (D3553, MBL; WB 1:1000) (Onoue et al., 2014), rat monoclonal anti-Dab1 antibody 4H11 (D354-3, MBL; WB 1:1000) (Onoue et al., 2014), mouse monoclonal anti-CTR 12C10 (MABN2428, Merck Millipore, WB 1:500) (Kohno et al., 2015), rabbit monoclonal anti-Nrp1 (ab81321, Abcam, RRID:AB_1640739; WB 1:1000, IHC 1:500), goat anti-VLDLR (AF2258, R\&D Systems, RRID:AB_2288612; WB 1:1000, IHC 1:500, IP 1:300), rabbit monoclonal anti-ApoER2 (ab108208, Abcam, RRID:AB_10862841; WB 1:1000), mouse monoclonal antiphosphotyrosine 4G10 (05-321, Merck Millipore, RRID:AB_309678; WB 1:2000), and goat polyclonal TLE (sc-13373, Santa Cruz Biotechnology, RRID:AB_2203721; IP 1:300).

Plasmids. The expression plasmids for Reelin- $\Delta 6$ and AP-RR78C (Kohno et al., 2015); for AP-RR38C, VLDLR-II-GFP, and ApoER2-GFP (Hibi et al., 2009); and for AP-RR36 (Uchida et al., 2009) have been previously described. The Reelin cDNA construct, pCrl (kindly gifted from Prof. T. Curran) (D'Arcangelo et al., 1997), was used to express WT mouse Reelin and as a template for PCR amplification. For site-directed mutagenesis, point mutations were introduced into the CTR coding sequence by standard PCR. To construct the expression plasmid for preprosegment of furin (ppFurin), the cDNA coding for the preprosegment of the mouse furin (Met1-Val109) was amplified from pCMV-mFurin (kindly gifted from Prof. K. Nakayama), and the PCR product was cloned into a pCAGGS vector (kindly gifted from Prof. J. Miyazaki) (Niwa et al., 1991). The expression plasmids of HA-tagged Nrp1 and Nrp2 have been previously described (Kanatani et al., 2015). The deletion mutants of HA-tagged Nrp1 were constructed into a pCAGGS vector, and all mutants lacked the following domains: $\Delta \mathrm{a} 1$, Asp25-Glu146; $\Delta \mathrm{a} 2$, Cys147-Lys274; $\Delta \mathrm{b} 1$, Cys275-Pro430; $\Delta \mathrm{b} 2$, Cys431-Thr589; $\Delta \mathrm{AB}$, Asp25-Thr589; and $\triangle \mathrm{ABC}$, Asp25-Asp796. For the construction of both Fc-tagged Nrp1 and Nrp2, the cDNA coding for the extracellular domain of either mouse Nrp1 (Met1-Pro856) or mouse Nrp2 (Met1Glu802) was cloned into the Igtag vector (kindly provided by Prof. J. G. Flanagan). Both pCAGGS-EGFP and pCAGGS-Reelin have been previously described (Kubo et al., 2010). pK031.TRE-Cre (Addgene, plasmid 
\#69136, RRID:Addgene_69136) and pK038.CAG-loxP-stop-loxP-EGFPires-tTA-WPRE (Addgene, plasmid \#85006, RRID:Addgene_85006) were both kindly gifted from Prof. T. Iwasato (Mizuno et al., 2014). To construct pCAG-loxP-stop-loxP-mGFP-ires-tTA-WPRE, the cDNA of membrane GFP was excised from pCAG-mGFP (kindly gifted from Prof. C. Cepko; Matsuda and Cepko, 2007; Addgene, plasmid \#14757, RRID:Addgene_14757), and the cDNA was subcloned into pK038 by SalI/EcoRV digestion. pSilencer 3.0H-1 (Thermo Fisher Scientific) was used for the construction of the knockdown (KD) vector. The shRNA target for Nrp1 was 5' -GGTGAAATCGGAAAAGGAA-3'. The shRNAresistant HA-Nrp1 was generated using a PrimeSTAR Mutagenesis Basal Kit (Takara) with the primers $5^{\prime}$-AGATTGGTAAGGGTAAC

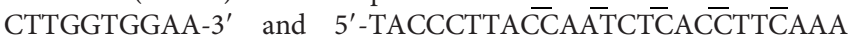
AA-3' (mutated nucleotides are underline $\overline{\text { ) }}$. The expression plasmid of Myc-DDK-tagged VLDLR-I (MR226657) was obtained from Origene, and the insert was subcloned into pEGFP-N1 (Clontech/Takara). The expression plasmid of pcDNA3.1-APP was kindly gifted by K. Shirotani, and the expression plasmid of Robol was kindly gifted by C. Hanashima (Gonda et al., 2013). The expression plasmids of Ephrin-A5, Ephrin-B1, EphA3, EphB2, and AP-VEGF164 were kindly gifted by Prof. J. G. Flanagan, and the EphA3 cDNA was subcloned into pEF-BOS (Mizushima and Nagata, 1990), while the cDNA of EphB2 and APVEGF164 was subcloned into pcDNA3.1/zeo(+) (Thermo Fisher Scientific). pCAGGS-AP-Sema3A has been previously described (Suto et al., 2005).

SDS-PAGE, WB, and Dab1 phosphorylation assay. SDS-PAGE, WB, and Dab1 phosphorylation assay were performed as previously described (Nakano et al., 2007; Kohno et al., 2015).

Immunostaining. For the IHC experiment, mice were perfusionfixed with $4 \%$ PFA in PBS. The brains were postfixed with $4 \%$ PFA in PBS overnight and cryoprotected in $30 \%$ sucrose in PBS. The fixed brains were frozen in a Tissue-Tek OCT compound (Sakura Finetek) using dry ice and stored at $-80^{\circ} \mathrm{C}$ until further use. The frozen brains were coronally sectioned at $20-30 \mu \mathrm{m}$ using a cryostat (CM 1850; Leica Microsystems). The sections were incubated with a $2 \%$ BSA in PBS containing $0.1 \%$ Triton X-100 at room temperature for $30 \mathrm{~min}$ and incubated with the primary antibodies diluted with PBS containing $0.1 \%$ Triton X-100 and $2 \% \mathrm{BSA}$ at $4^{\circ} \mathrm{C}$ overnight. The sections were then washed with PBS containing $0.05 \%$ Tween 20 (PBS-T) and incubated with Alexa-488- and Alexa-568-conjugated secondary antibodies (1:500; Thermo Fisher Scientific) at room temperature for $1 \mathrm{~h}$. The sections were then counterstained with Hoechst $33342(2 \mu \mathrm{g} / \mathrm{ml}$; Thermo Fisher Scientific) and mounted in fluorescence mounting medium (Dako).

COS-7 cells expressing Nrp1 were incubated with AP-fused Reelin for $90 \mathrm{~min}$ and washed with HBAH buffer (HBSS containing $0.5 \mathrm{mg} / \mathrm{ml}$ BSA, $20 \mathrm{~mm}$ HEPES, and $0.1 \% \mathrm{NaN}_{3}$ ) 6 times and fixed with $4 \%$ PFA in $\mathrm{PBS}$ for $10 \mathrm{~min}$. Cells were incubated with the primary antibodies diluted with PBS containing 2\% BSA without membrane permeabilization at $4^{\circ}$ $\mathrm{C}$ overnight. The cells were then washed with PBS-T and incubated with Alexa-488- and Alexa-568-conjugated secondary antibodies (1:500) at room temperature for $2 \mathrm{~h}$. The cells were then counterstained with Hoechst 33342 and mounted in fluorescence mounting medium.

Fluorescence images were captured using either Biorevo BZ-9000 (Keyence) or LSM 800 (Carl Zeiss). For the quantitative analysis of Reelin binding to cells, the mean intensity of the cell was measured using ImageJ software (National Institutes of Health, RRID:SCR_003070). For the quantification of the relative position of GFP-labeled neurons, cortical thickness was divided into 10 equal bins from the top of the $\mathrm{CP}$ to the ventricular zone (VZ). The number of cells in each bin was counted and divided by the number of total GFP-labeled cells. For the quantification of dendrite length and branching points, confocal images were flattened using the maximum intensity projection method from Zen software (Carl Zeiss, RRID:SCR_013672). The total length of apical dendrites and the number of branching points were measured using ImageJ software.

Cell-surface AP-fused Reelin-binding analysis. COS-7 cells expressing transmembrane receptors were incubated with AP-fused Reelin proteins for $90 \mathrm{~min}$ and washed with HBAH buffer 6 times. Cells were fixed with 1\% PFA in PBS for 1 min and washed 3 times with HBS (150 mM
$\mathrm{NaCl}$ and $20 \mathrm{~mm}$ HEPES, pH 7.0). Cells were then heated for $90 \mathrm{~min}$ at $68^{\circ} \mathrm{C}$ to inactivate the endogenous AP and washed twice with AP buffer (100 mM Tris, pH 9.5, $5 \mathrm{~mm} \mathrm{MgCl}_{2}$, and $100 \mathrm{~mm} \mathrm{NaCl}$ ). AP-fused Reelin on the cell surface was detected by NBT/BCIP solution (AP buffer containing $0.33 \mathrm{mg} / \mathrm{ml} \mathrm{NBT}$ and $0.17 \mathrm{mg} / \mathrm{ml} \mathrm{BCIP}$ ) on ice. Images were captured using an SZX7 microscope (Olympus) equipped with a DP27 digital camera (Olympus). For the quantitative analysis of Reelin binding to cells, the mean intensity of cell surface-bound AP-fused Reelin was measured using ImageJ software.

IP. Transfected COS-7 cells were lysed with radioimmunoprecipitation assay (RIPA) buffer (50 mM Tris- $\mathrm{HCl}, \mathrm{pH} 8.0,150 \mathrm{~mm} \mathrm{NaCl}, 0.1 \%$ SDS, $1 \%$ NP-40, and $0.5 \%$ sodium deoxycholate). Cell lysates were then centrifuged at $17,800 \times g$ for $10 \mathrm{~min}$ at $4^{\circ} \mathrm{C}$, and the supernatants were mixed with anti-GFP antibody and protein G Sepharose (GE Healthcare) for $2 \mathrm{~h}$ at $4^{\circ} \mathrm{C}$. The reaction mixture was centrifuged, and the precipitate was washed with RIPA buffer 4 times and dissolved with a $1 \times$ SDS sample buffer.

The neocortex was excised from P0 mice brains and collected in HBSS. The tissue was triturated with a 27 -gauge needle on ice, and the suspension was centrifuged at $700 \times g$ for $5 \mathrm{~min}$ at $4^{\circ} \mathrm{C}$. The supernatant was collected and centrifuged at $17,800 \times g$ for $10 \mathrm{~min}$ at $4^{\circ}$ C. The precipitate was lysed with N-PER Neuronal Protein Extraction Reagent (Thermo Fisher Scientific), and the lysates were incubated with anti-VLDLR antibody and protein G Sepharose for $2 \mathrm{~h}$ at $4^{\circ} \mathrm{C}$. The precipitate was washed with RIPA buffer 4 times and dissolved with $1 \times$ SDS sample buffer. Anti-TLE antibodies were used as a negative control.

Pull-down experiment. The supernatants containing the Fc-fused protein were incubated with protein G Sepharose for $2 \mathrm{~h}$ at $4^{\circ} \mathrm{C}$. Beads were washed with $20 \mathrm{~mm}$ phosphate buffer, $\mathrm{pH} 7.0,4$ times, followed by elution using $100 \mathrm{~mm}$ glycine- $\mathrm{HCl}, \mathrm{pH}$ 2.7. The concentrations of Fcfused protein were quantified using Protein Assay Bradford Reagent (Wako), according to the manufacturer's instructions. Next, $10 \mu \mathrm{g} \mathrm{Fc-}$ fused proteins were incubated with AP-fused proteins and protein $G$ Sepharose for $2 \mathrm{~h}$ at $4^{\circ} \mathrm{C}$. Beads were washed with RIPA buffer 3 times and then dissolved with $1 \times$ SDS sample buffer.

Cell-surface biotinylation. Cultured cells were washed twice with icecold PBS containing $0.33 \mathrm{~mm} \mathrm{MgCl}_{2}$ and $0.9 \mathrm{~mm} \mathrm{CaCl}_{2}\left(\mathrm{PBS}^{+}\right)$and incubated with $1 \mathrm{mg} / \mathrm{ml}$ Sulfo-NHS-Biotin (Thermo Fisher Scientific) in $\mathrm{PBS}^{+}$for $40 \mathrm{~min}$ on ice. To quench the nonreacting NHS-biotin, cells were washed with $100 \mathrm{~mm}$ glycine in PBS for $5 \mathrm{~min}$. Cells were lysed with RIPA buffer, and the lysates were centrifuged at $17,800 \times g$ for $10 \mathrm{~min}$ at $4^{\circ} \mathrm{C}$. The supernatants were incubated with avidin agarose (Thermo Fisher Scientific) for $1 \mathrm{~h}$ at $4^{\circ} \mathrm{C}$. Beads were then washed with RIPA buffer 3 times and dissolved with $1 \times$ SDS sample buffer.

In utero electroporation. In utero electroporation was performed as previously described (Tabata and Nakajima, 2001, 2008). Time-pregnant mice were anesthetized using pentobarbital sodium (Tokyo Chemical Industry, $0.06 \mathrm{mg} / \mathrm{g}$ body weight) by intraperitoneal administration. A 1$2 \mu \mathrm{l}$ of DNA plasmid solution containing $0.01 \%$ fast green was then injected into the lateral ventricle of embryos using a mouth-controlled micropipette (Drummond). Square electric pulses ( $31 \mathrm{~V}, 50 \mathrm{~ms}, 4$ times) were applied using an electroporator (CUY21EDIT, Bex) with a forceps electrode (LF650P5, Bex). For sparse labeling, we used the Supernova System as previously described (Mizuno et al., 2014). The final concentration of plasmid DNAs is described in Table 1.

Experimental design and statistical analysis. All quantitative data were expressed as mean \pm SEM, and individual data points are plotted. The statistical methods and their detail descriptions are described in the figure legends. The normality of the dataset was analyzed by ShapiroWilk normality test. For datasets with small sample size, which thus is not subject to Shapiro-Wilk normality test, we assume that it might show normality because the experimental datasets from the same kind of experimental population showed normality, and we planned the experiments on this assumption. All of the data are two-tailed. For direct comparisons, the data were analyzed using a one-sample $t$ test or MannWhitney $U$ test. For multiple comparisons, one-way ANOVA was performed, followed by Tukey's post hoc test. All statistical analyses were performed using Prism (GraphPad Software, RRID:SCR_002798). 
Table 1. Final concentrations of plasmid DNAs ${ }^{a}$

\begin{tabular}{|c|c|c|c|c|c|c|c|}
\hline & pCAGGS-EGFP & pSilencer-control & pSilencer-Nrp1 & pCAGGS1 & pCAGGS-Nrp1WT* & pCAGGS-Nrp1 $\Delta \mathrm{a} 2^{*}$ & \\
\hline \multicolumn{8}{|l|}{ Conventional labeling } \\
\hline control & 1.5 & 2.0 & - & 1.5 & - & - & \\
\hline Nrp1KD & 1.5 & - & 2.0 & 1.5 & - & - & \\
\hline Nrp1KD+Nrp1WT* & 1.5 & - & 2.0 & - & 1.5 & - & \\
\hline \multirow[t]{2}{*}{$\operatorname{Nrp1KD}+\operatorname{Nrp} 1 \Delta \mathrm{a} 2^{*}$} & 1.5 & - & 2.0 & - & - & 1.5 & \\
\hline & pSilencer-control & pSilencer-Nrp1 & pCAGGS1 & pCAGGS-Nrp1WT* & pCAGGS-Nrp1 $\Delta \mathrm{a} 2^{*}$ & pCAG-Is|-mGFP-Ires-tTA-WPRE & TRE-Cre \\
\hline \multicolumn{8}{|l|}{ Sparse labeling } \\
\hline control & 2.0 & - & 1.5 & - & - & 2.0 & 0.005 \\
\hline Nrp1KD & - & 2.0 & 1.5 & - & - & 2.0 & 0.005 \\
\hline Nrp1KD+Nrp1WT* & - & 2.0 & - & 1.5 & - & 2.0 & 0.005 \\
\hline \multirow[t]{2}{*}{$\operatorname{Nrp1KD}+\operatorname{Nrp} 1 \Delta \mathrm{a} 2^{*}$} & - & 2.0 & - & - & 1.5 & 2.0 & 0.005 \\
\hline & pCAGGS-EGFP & pCAGGS-Reelin & pSilencer-control & pSilencer-Nrp1 & & & \\
\hline \multicolumn{8}{|c|}{ Ectopic expression of Reelin } \\
\hline Reelin + control & 0.8 & 6.0 & 2.0 & - & & & \\
\hline Reelin + Nrp1KD & 0.8 & 6.0 & - & 2.0 & & & \\
\hline
\end{tabular}

${ }^{a}$ The concentrations are shown in $\mathrm{mg} / \mathrm{ml}$.

\section{Results}

\section{Reelin with an intact CTR binds to Nrp1}

WC cleavage occurs between the Arg3455 and Ser3456 of the Reelin CTR and releases a six-amino acid peptide, which contains two Arg residues (R3458 and R3459; Fig. 1A) (Kohno et al., 2015). Since extracellular signaling proteins frequently interact with the basic domains of negatively charged molecules, we prepared culture supernatants containing AP-fused protein that comprises Reelin repeats 7 and 8 plus CTR (AP-RR78C-FL) or its mutants (Fig. 1A). AP-RR78C- $\Delta 6$ lacked the last six residues. AP-RR78C-RA contained one mutation (R3455A), which provides resistance to WC cleavage (Kohno et al., 2015). In APRR78C-mut3, three Arg residues were replaced with Ala (R3455/ $3458 / 3459 \mathrm{~A})$ to test the importance of the basic residues. We then tested the interaction between these AP-fusion proteins and cultured cortical neurons. AP-RR78C-RA bound strongly to the neurons, as previously demonstrated (Fig. 1B) (Kohno et al., 2015). AP-RR78C-mut3 interacted with the neurons much less strongly than AP-RR78C-RA (Fig. $1 B, C$ ), suggesting that R3458 and R3459 contribute to the interaction between Reelin and the neuronal cell membrane.

To identify a protein that specifically binds to Reelin-FL, we adopted a candidate approach. We expressed various transmembrane proteins in COS-7 cells and examined their binding to AP-RR78C-RA. Amyloid precursor protein (APP), EphrinB1, and EphB2 (Fig. 1D) have been previously reported as Reelin-binding molecules (Hoe et al., 2009; Senturk et al., 2011; Bouche et al., 2013); however, they did not bind to APRR78C- $\Delta 6$ or AP-RR78C-RA (Fig. 1D). We also examined the binding activity of AP-RR78C-RA to Robo1, Ephrin-A5, and EphA3, but we could not detect any specific binding (Fig. 1D). Conversely, AP-RR78C-RA bound strongly to Nrp1-expressing COS-7 cells, while AP-RR78C- $\Delta 6$ bound only weakly to Nrp1-expressing COS-7 cells (Fig. 1D), suggesting that Nrp1 is a molecule that binds to Reelin-FL.

Nrp1 is a receptor for semaphorin 3A (Sema3A) and vascular endothelial growth factor A (VEGF-A) (He and Tessier-Lavigne, 1997; Kolodkin et al., 1997; Soker et al., 1998). It also binds to synthetic peptides that contain consecutive Arg residues (Hong et al., 2007). AP-RR78C-RA bound weakly to Nrp-2-expressing
COS-7 cells (Fig. 1D). The binding of AP-RR78C-mut3 to Nrp1 was markedly lower than that of AP-RR78C-RA (Fig. 1E,F). To determine whether AP-RR78C-RA directly binds to Nrp, a pulldown assay using Fc-fused Nrp was performed (Fig. $1 G$ ), and we found that AP-RR78C-RA, but not AP-RR78C- $\Delta 6$, coprecipitated with Nrp1-Fc (Fig. $1 H$, lanes 5 and 6). In contrast, binding to Nrp2-Fc was very weak with little difference between APRR78C- $\Delta 6$ and AP-RR78C-RA (Fig. $1 H$, lanes 7 and 8). These results suggest that AP-RR78C-RA directly interacts with Nrp1 and that the basic residues of the CTR contribute to this interaction.

We next confirmed that Reelin-FL binds to Nrp1. To inhibit the endogenous proprotein convertase family proteases that mediate WC cleavage, the expression vector for Reelin was cotransfected with that for the ppFurin, which strongly inhibits the activity of the proprotein convertase family in the secretory pathway (Zhong et al., 1999). Reelin-FL obtained by this method was detected by the $12 \mathrm{C} 10$ antibody, which reacts only with intact CTR (Fig. 2A) (Kohno et al., 2015). Reelin-FL, but not Reelin- $\Delta 6$, bound to Nrp-1-expressing COS-7 cells (Fig. $2 D$ ), indicating that Reelin-FL interacts with Nrp1 and that WC cleavage abrogates this interaction.

Nrp1 has two CUB domains (a1 and a2), two coagulation factor V and VIII domains (b1 and b2), and a MAM domain in its extracellular region (Fig. 2B) (He and Tessier-Lavigne, 1997; Kolodkin et al., 1997). To identify the Reelin-binding domain of Nrp1, each of the deletion mutants of Nrp1 shown in Figure $2 B$ was expressed in COS-7 cells. Their expression levels on the cell surface, assessed by the surface biotinylation technique, were comparable, except for Nrp1 $\Delta$ al (Fig. 2C). Reelin-FL bound to $\operatorname{Nrp} 1 \Delta \mathrm{a} 1, \operatorname{Nrp} 1 \Delta \mathrm{a} 2$, and $\operatorname{Nrp} 1 \Delta \mathrm{b} 2$, but not to Nrp1 $\Delta \mathrm{b} 1$ (Fig. $2 D)$. Therefore, the b1 domain of Nrp1 is required for the binding to Reelin-FL. This property of Reelin-FL is similar to that of VEGF-A but different to that of Sema3A (Fig. 2E) (Gu et al., 2002).

To examine the contribution of Nrp1 in the interaction between Reelin and neurons, we performed KD experiments by introducing the shRNA vector into primary cultured cortical neurons. The expression of Nrp1 decreased in the neurons in which the shRNA vector for Nrp1 was introduced (Nrp1KD neurons) (Fig. 3A,B). We incubated the neurons with either AP- 
A

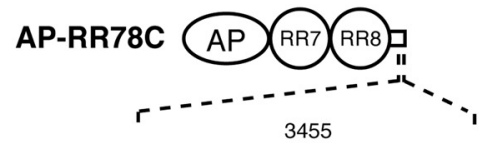

$\Delta 6:$ FYNRRRR*

FL: FYNRRRRSLRRYP*

RA: FYNRRRASLRRYP * mut3: FYNRRRASLAAYP*
B

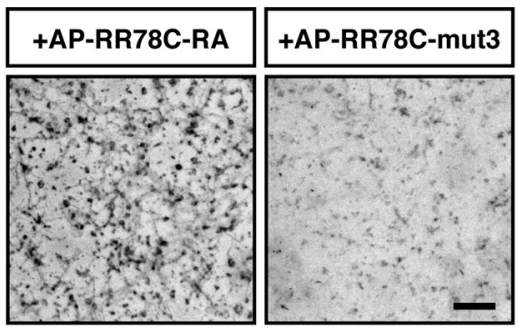

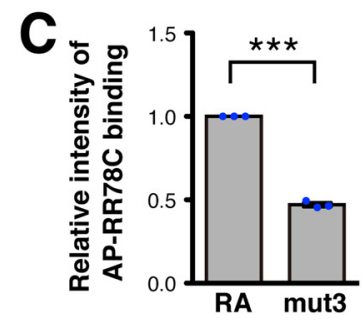
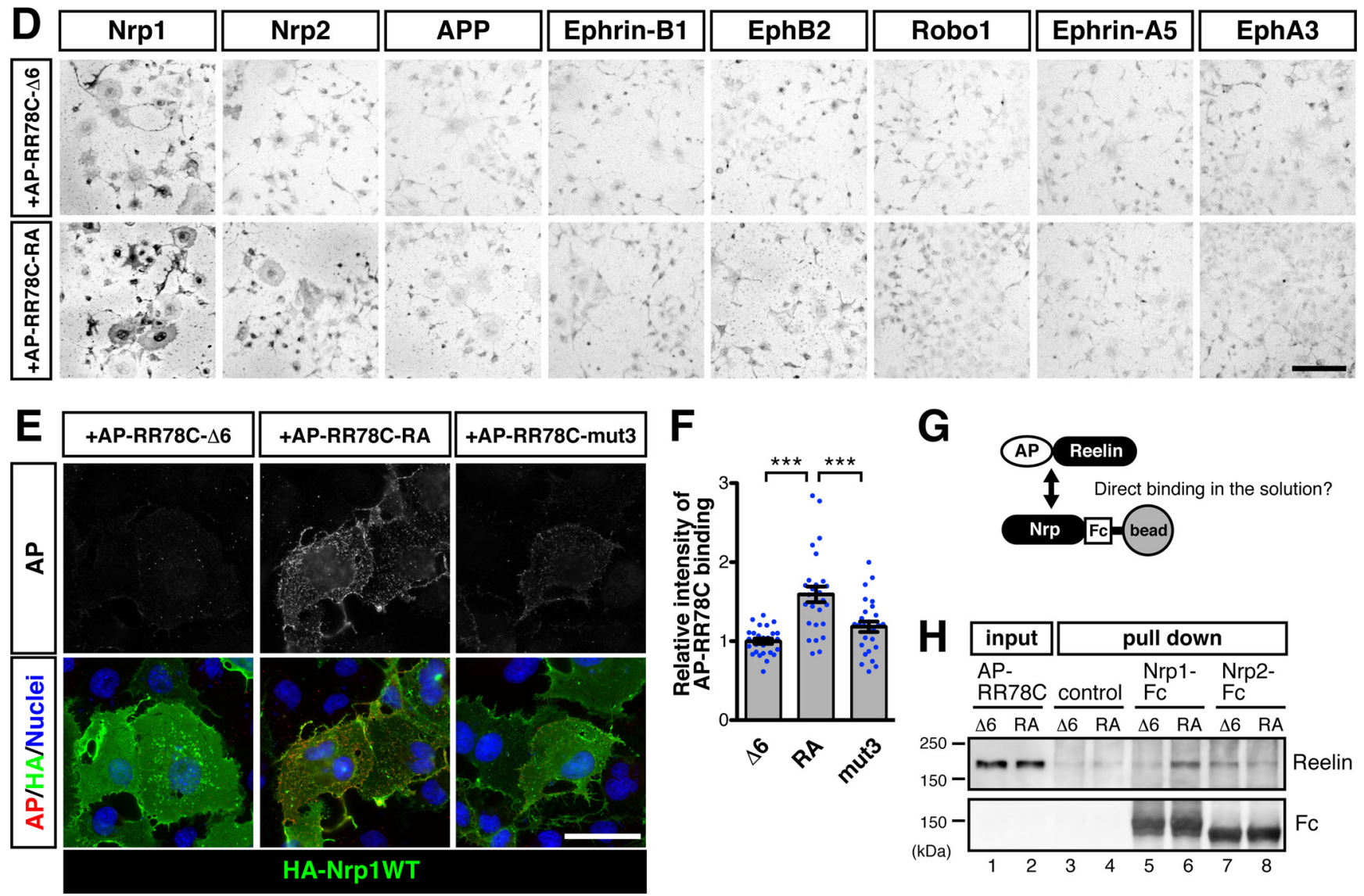

$\mathbf{G}$
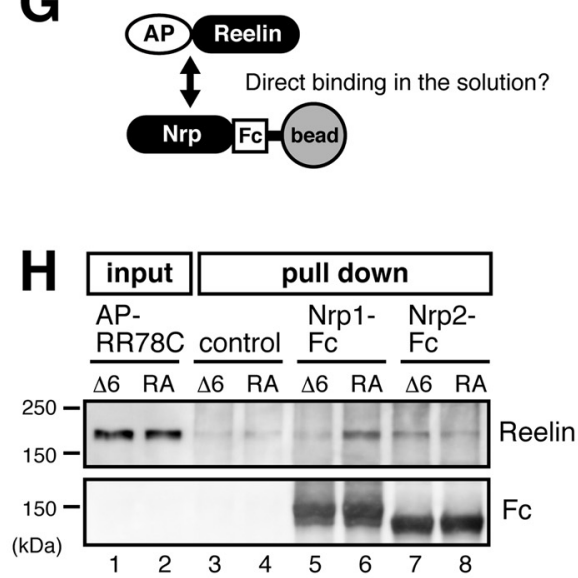

Figure 1. Reelin interacts with Nrp1. A, Schematic diagram of AP-fused Reelin proteins. Underlining indicates the consensus sequence of the proprotein convertase family proteases. Bold indicates mutated amino acid residues. RR, Reelin repeat. $B, A P$ staining of primary cultured cortical neurons. The affinity of AP-RR78C-mut3 to cultured cortical neurons was decreased compared with that of AP-RR78C-RA. Scale bar, $100 \mu \mathrm{m}$. C, Quantification of the binding of AP-RR78C-RA and AP-RR78C-mut3 to cultured cortical neurons. $t_{(2)}=43.30, p=0.0005$ (one-sample $t$ test). $n=3$ experiments. ${ }^{* * *} p<0.001$. D, AP staining of COS-7 cells expressing various transmembrane proteins. AP-RR78C-RA, but not AP-RR78C- $\Delta 6$, strongly bound to Nrp1-expressing cells. Scale bar, $200 \mu \mathrm{m}$. $\boldsymbol{E}$, Immunofluorescence staining of cell surface-bound AP-fused Reelin on COS-7 cells expressing HA-Nrp1WT. AP-RR78C-RA bound to Nrp1-transfected cells, but not to nontransfected cells. The affinity of AP-RR78C-mut3 was decreased compared with that of AP-RR78C-RA. Scale bar, $50 \mu \mathrm{m}$. $\boldsymbol{F}$, Quantification of the binding of AP-RR78C proteins to COS-7 cells expressing Nrp1WT. $F_{(2,78)}=18.12$ (one-way ANOVA). ${ }^{* *} p<0.001$ (Tukey's post hoc test). $n=27$ cells from three independent experiments. $G$, Schematic drawing of the pull-down assay. AP-fused Reelin was mixed with Fc-fused Nrp, and the protein complex was precipitated using Protein G beads. $\boldsymbol{H}$, Pull-down assay using Fc-fused Nrp1 or Nrp2. AP-RR78C-RA strongly bound to Nrp1-Fc, but not to Nrp2-Fc. Molecular mass markers $(\mathrm{kDa})$ are shown on the left of the panels.

RR78C- $\Delta 6$ or AP-RR78C-RA, and their binding was evaluated. It was revealed that the binding of AP-RR78C-RA to Nrp1KD neurons was significantly lower than that to control neurons (Fig. $3 C, D$ ). AP-RR78C- $\Delta 6$ did not bind to either the Nrp1KD or control neurons (Fig. $3 C$ ). These results suggest that Nrp1 is a major binding molecule of Reelin-FL in cultured cortical neurons.

Nrp1 forms a functional complex with Reelin receptors

Nrp1 is a multifunctional coreceptor molecule that forms a complex with various receptors, including plexin, the VEGF receptor, and L1CAM (Pellet-Many et al., 2008). To examine whether Nrp1 forms a complex with canonical Reelin receptors, HA-Nrp1 was coexpressed with ApoER2-GFP, VLDLR-
GFP, or GFP, and IP was performed using anti-GFP antibodies. ApoER2-GFP and VLDLR-GFP, but not GFP alone, were coprecipitated with HA-Nrp1 (Fig. 4A), indicating that canonical Reelin receptors can form a complex with Nrp1. Since CTR truncation attenuates Reelin signaling via VLDLR ( $\mathrm{Ha}$ et al., 2017), we focused on the relationship between Nrp1 and VLDLR in the subsequent experiments. To determine which domain of Nrp1 is required for its interaction with VLDLR, deletion mutants of Nrp1 were prepared, as shown in Figure $4 B$. The IP experiments revealed that $\operatorname{Nrp} 1 \triangle \mathrm{AB}$, but not Nrp1 $\triangle \mathrm{ABC}$, formed a complex with VLDLR-GFP (Fig. 4C), suggesting that Nrp1 interacts with VLDLR via its MAM domain. Finally, we confirmed that Nrp1 and VLDLR formed a complex in brain lysates. Endogenous Nrp1 was coimmuno- 
A

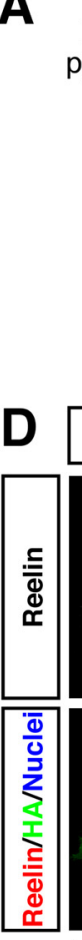

Reelin ++++ ppFurin $-+\quad+$

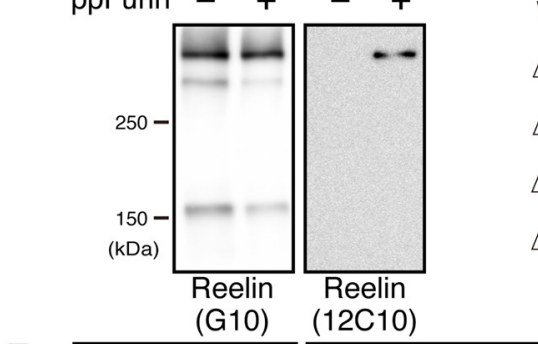

B

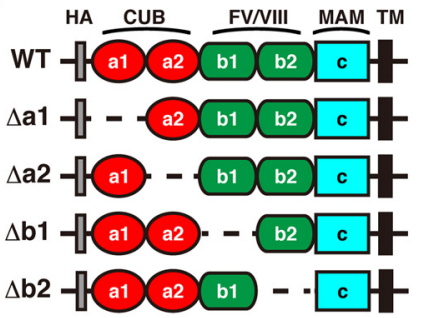

C

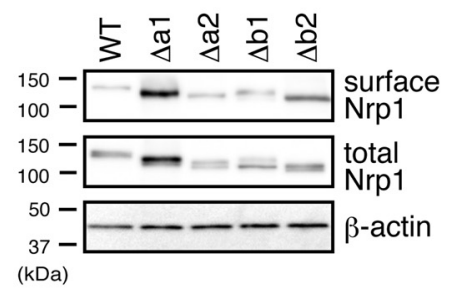

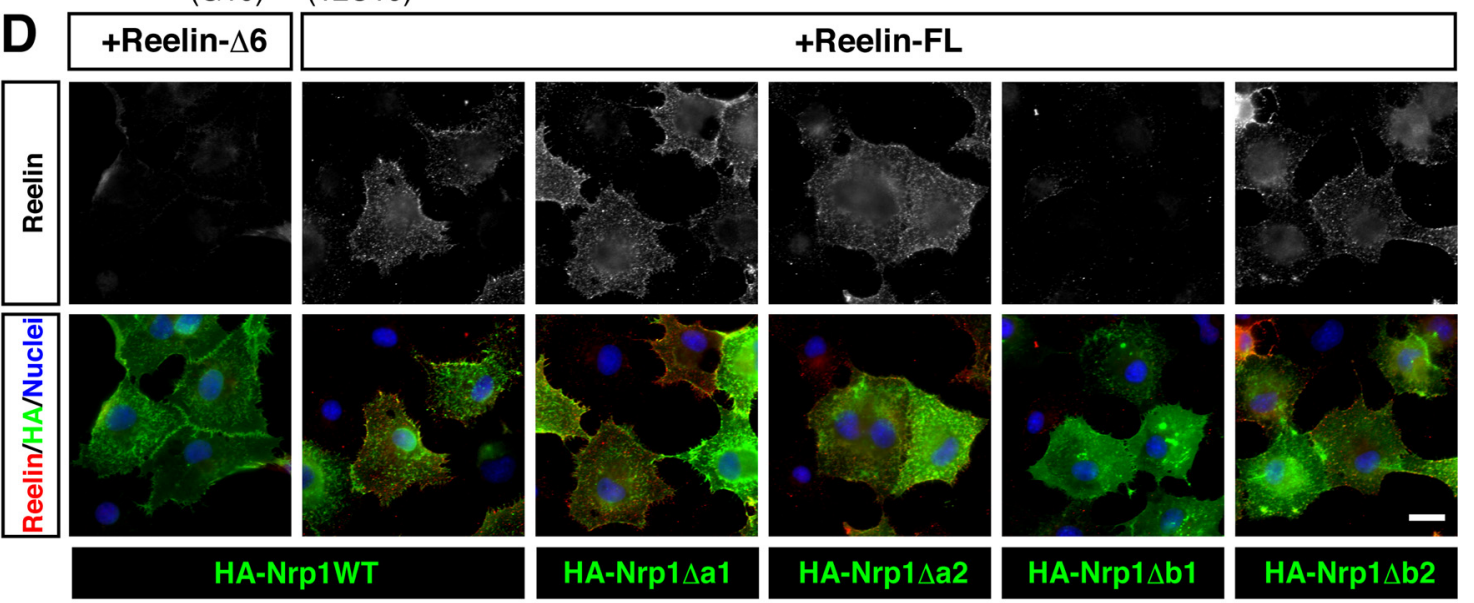

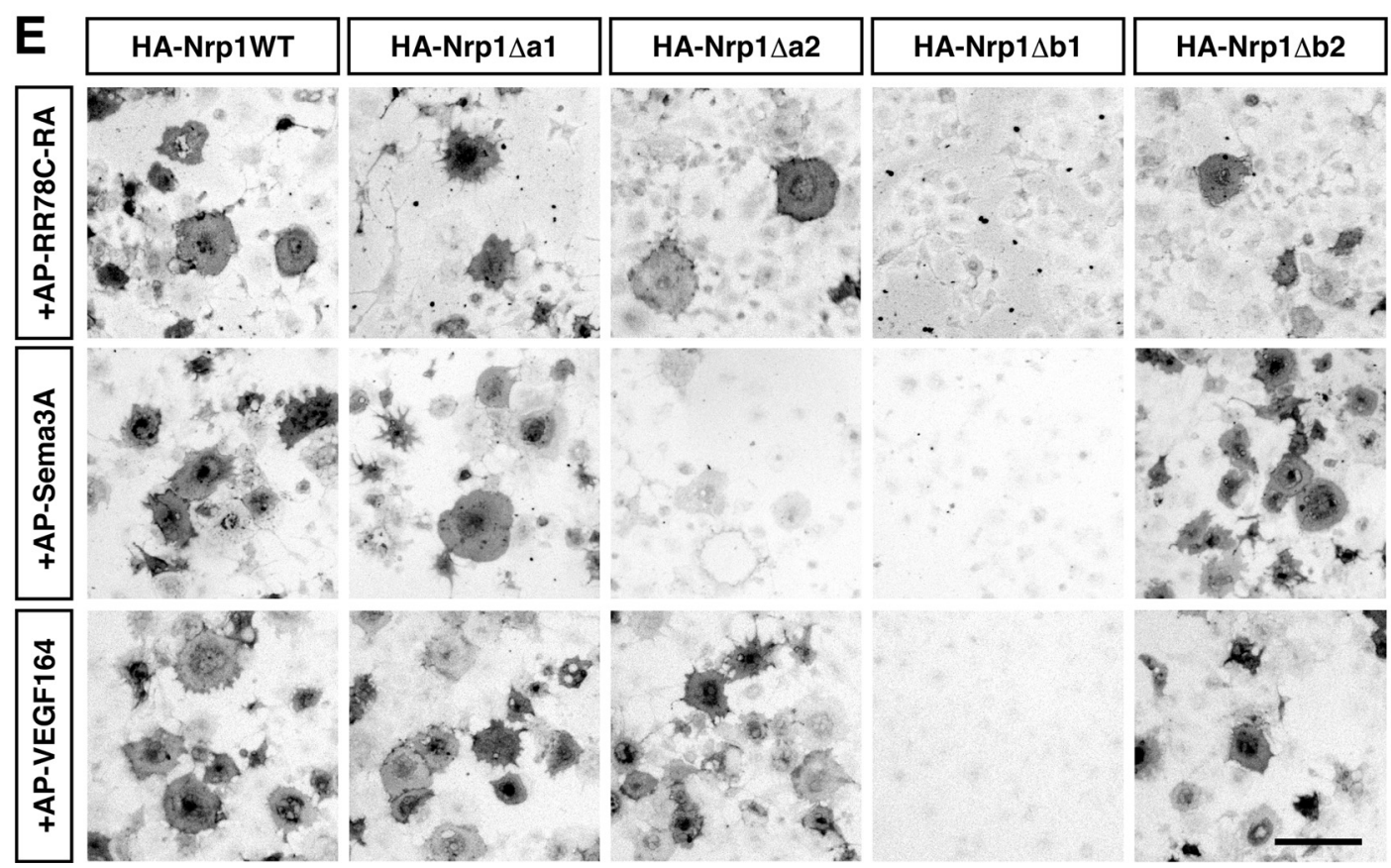

Figure 2. The b1 domain of Nrp1 is required for its binding with Reelin. $A$, WB analysis of Reelin- $\Delta 6$ and Reelin-FL. Reelin was coexpressed with an empty vector or ppFurin in HEK293T cells and detected using either anti-Reelin (G10) or anti-intact CTR (12C10) antibodies, respectively. The WC cleavage of Reelin was inhibited by coexpression of ppFurin. Molecular mass markers $(\mathrm{kDa})$ are shown on the left of the panels. B, Schematic diagram of HA-tagged Nrp1WT and its deletion mutants. C, Biotinylation assay to quantitate cell-surface expression of Nrp1 and its mutants. COS-7 cells expressing the proteins indicated above each lane were incubated with Sulfo-NHS-Biotin, washed, and lysed. Biotinylated proteins were precipitated with avidin beads. Precipitated proteins (top) or cell lysates (middle, bottom) were analyzed with WB with anti-HA (top, middle) or anti- $\beta$-actin (bottom) antibodies, respectively. Molecular mass markers (kDa) are shown on the left of the panels. D. Immunofluorescence staining of cell surface-bound Reelin- $\Delta 6$ or Reelin-FL on COS-7 cells expressing Nrp1WT or its mutants. The b1 domain of Nrp1 is required for binding with Reelin-FL. Scale bar, $20 \mu \mathrm{m}$. E, AP staining of COS-7 cells. Either AP-RR78C-RA, AP-Sema3A, or AP-VEGF164 was incubated with COS-7 cells expressing the indicated Nrp1 mutants, and cell surface-bound AP proteins were detected. The b1 domain is required for binding with Reelin, Sema3A, and VEGF164. Scale bar, $200 \mu \mathrm{m}$.

precipitated with VLDLR (Fig. 4D), indicating that a Nrp1/VLDLR complex exists in vivo.

The localization of VLDLR and Nrp1 in the developing mouse neocortex was carefully compared. At embryonic day 14.5 (E14.5) and E16.5, Nrp1 was localized in the intermediate zone, while VLDLR was mainly localized in the MZ and in the upper region of the CP (Fig. 4E). At postnatal day 0 (P0), Nrp1 was colocalized with VLDLR in superficial 
layers (Fig. 4E,F). These results suggest that the expression of Nrp1 is spatially controlled during development and that neurons in the superficial layers are able to receive ReelinFL-dependent signals.

\section{Reelin-FL preferentially binds to the VLDLR/ Nrp1 complex}

The expression levels of Nrp1, VLDLR, ApoER2, and Dab1 in the developing neocortex were investigated by WB analysis. The expression levels of Nrp1 and ApoER2 were slightly decreased at P0 than at the embryonic stages (Fig. 5A). Interestingly, there were two bands on the VLDLR blot at E16.5 and P0, but the upper band was faint at E14.5 (Fig. 5A). Presumably, these bands were derived from alternative splicing that generates two major variants, VLDLR-I and VLDLR-II (Sakai et al., 2009). VLDLR-II does not have an O-linked sugar domain encoded in exon 16 (Sakai et al., 2009). Both VLDLR-I and VLDLR-II expressed in COS-7 cells bound to the receptor-binding fragment of Reelin (Fig. 5B,C). VLDLR-I interacted with Nrp1 more strongly than VLDLR-II (Fig. 5D). Therefore, it is plausible that the O-linked sugar domain of VLDLR-I plays a role in its interaction with Nrp1.

To investigate whether Nrp1 affects the interaction between Reelin and VLDLR, we prepared culture supernatants containing AP-RR38C protein (Fig. $5 B$ ) by transfecting the expression vector for AP-RR38C with either a control (i.e., AP-RR38C- $\Delta 6$ ) or a ppFurin expression vector (i.e., AP-RR38C-FL). WB with $12 \mathrm{C} 10$ antibodies confirmed that AP-RR38C coexpressed with ppFurin retained the intact CTR (Fig. 5E). APRR38C-FL bound more strongly to Nrp1expressing COS-7 cells than AP-RR38C- $\Delta 6$ (Fig. $5 M, P, S)$. The affinity of AP-RR38C-FL to VLDLR-I was weaker than that of AP-RR38C- $\Delta 6$ to VLDLR-I (Fig. $5 H, K, T$ ), but the affinity to VLDLR-I/Nrp1 was comparable between AP-RR38CFL and AP-RR38C- $\Delta 6$ (Fig. 5I,L,T). Similar results were obtained when VLDLR-II was expressed with or without $\mathrm{Nrp1}$ (Fig. $5 \mathrm{~N}, \mathrm{O}$, $Q, R, U)$. Surface biotinylation experiments showed that the expression levels of cell-surface VLDLR-I were approximately the same, regardless of $\mathrm{Nrp1}$ (Fig. $5 F$ ). These results suggest that Nrp1 augments the binding of VLDLR to Reelin-FL, but not to Reelin- $\Delta 6$. It is important to note that the affinity of AP-RR38CFL to Nrp1 alone is lower than to VLDLR/Nrp1, indicated by the color developing time, which was much longer for $\operatorname{Nrp1}(24 \mathrm{~h})$ than for VLDLR/Nrp1 (5 h).

\section{Nrp1 participates in the degradation of Dab1}

To investigate whether Nrp1 contributes to the Reelin-induced phosphorylation of Dab1, Nrp1KD neurons were incubated with either Reelin-FL or Reelin- $\Delta 6$. Consistent with our previous work (Kohno et al., 2015), in control neurons, Reelin-FL and Reelin- $\Delta 6$ induced Dab1 phosphorylation at the same levels (Fig. 6A,B). Similarly, in Nrp1KD neurons, the phosphorylation levels of Dab1 induced by Reelin-FL and Reelin- $\Delta 6$ were approximately equal (Fig. 6A,B), suggesting that Nrp1 does not greatly contribute to the acute induction of Dab1 phosphorylation. However, the level of Dab1 in Nrp1KD neurons was significantly higher than that in the control neurons (Fig. 6A,C). This result suggests that Nrp1 is involved in the degradation of the phosphorylated Dab1 protein.

The interaction between Reelin and Nrp1 is required for the dendritic development of superficial-layer neurons

Signaling by Reelin-FL is required for dendritic development and the precise positioning of the superficial-layer neurons in the postnatal neocortex (Kohno et al., 2015; Ha et al., 2017). We analyzed whether Nrp1 is necessary for this event. Since total deletion of Nrp1 in the developing brain halts neuronal migration (Chen et al., 2008), we reduced the expression of Nrp1 by introducing an shRNA vector using in utero electroporation (Tabata and Nakajima, 2001, 2008) at E15.5. At P1, nearly all control neurons had developed beneath the MZ (Fig. 7A), as did the majority of Nrp1KD neurons (Fig. 7B). At P7, the Nrp1KD neurons were positioned beneath the MZ, but their positions were slightly shifted downward compared with the control neurons (Fig. 7G, $H, K)$. Nrp1 immunoreactivity was confirmed to be weaker in the Nrp1KD neurons than in the control neurons (Fig. $7 \mathrm{~L}$ ). Compared with the control neurons (Fig. $7 M, M^{\prime}$ ), the Nrp1KD neurons did not appropriately extend their apical dendrites to the MZ (Fig. $7 N, N^{\prime}$ ). Positional and morphologic defects of the Nrp1KD neurons were rescued by the expression of shRNA-resistant Nrp1 (Nrp1WT*; Fig. $7 I, K, O, O^{\prime}$ ). For quantitative analysis of the apical dendrite morphology, sparse labeling of the 
A

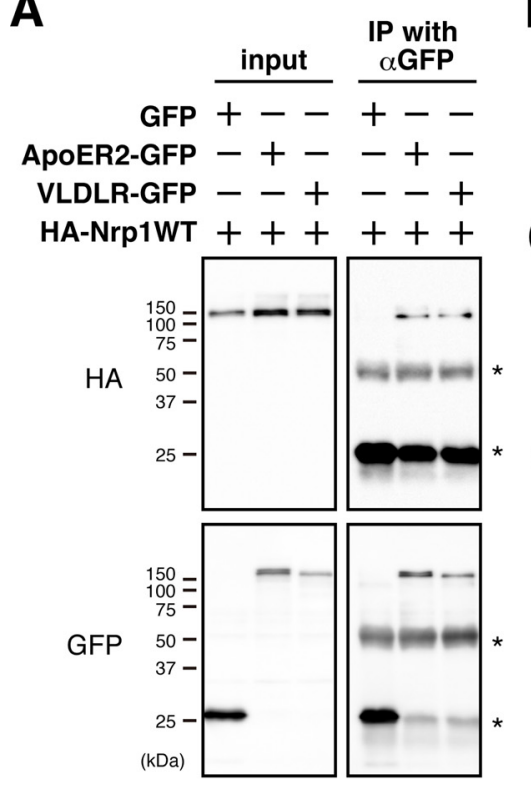

E

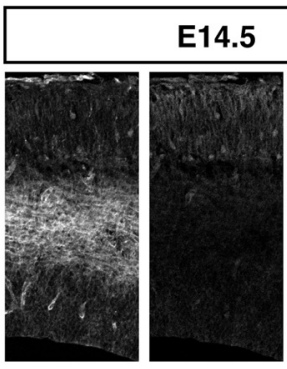

Nrp1
Nrp1 Nuclei

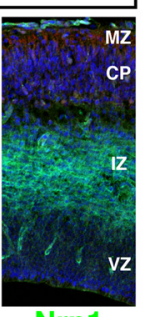

B

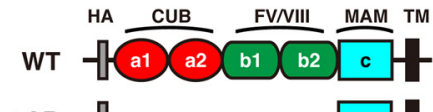

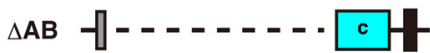

$\triangle A B C-1-\cdots$

C
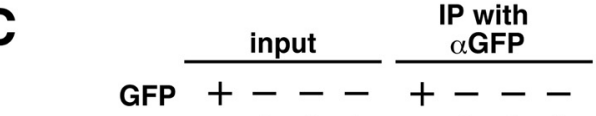

VLDLR-GFP -+++-+++

HA-Nrp1WT ++--++--

HA-Nrp1 $\triangle A B--+--+-$

HA-Nrp1 $\triangle A B C---+--+$

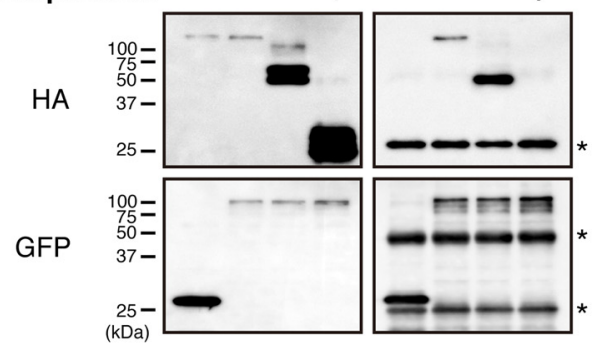

E16.5
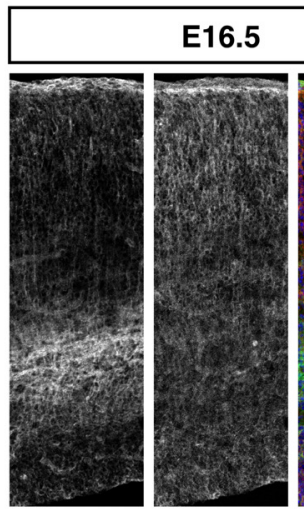

Nrp1

VLDLR

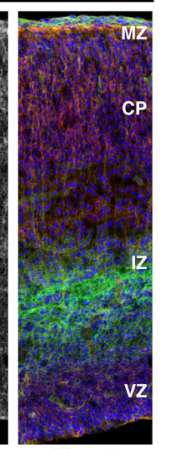

Nrp1

VLDLR Nuclei

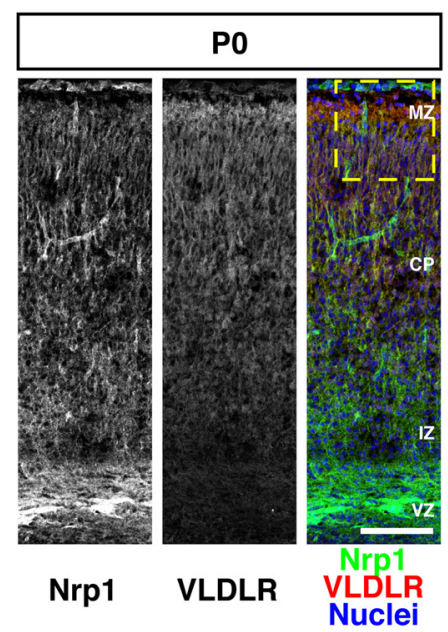

$\mathbf{F}$

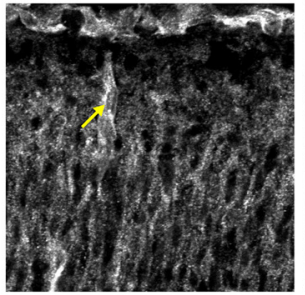

Nrp1

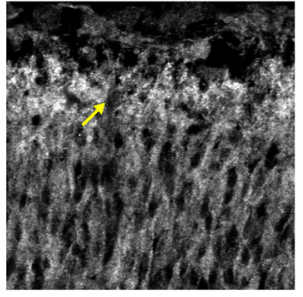

VLDLR

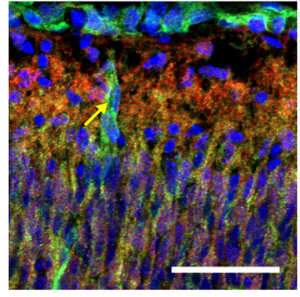

Nrp1/VLDLR/Nuclei

Figure 4. Nrp1 forms a complex with canonical Reelin receptors. A, Co-IP from COS-7 cells expressing ApoER2-GFP or VLDLR-GFP with HA-Nrp1WT. HA-Nrp1WT was coimmunoprecipitated with ApoER2-GFP or VLDLR-GFP. *Nonspecific lgG bands. Molecular mass markers $(\mathrm{kDa}$ ) are shown on the left of the panels. $\boldsymbol{B}$, Schematic diagram of HA-tagged Nrp1WT and its mutants. Nrp1 $\triangle A B$ does not have a1, a2, b1, and b2 domains. Nrp1 $\triangle A B C$ does not have most of the extracellular domains. C, Co-IP from COS-7 cells expressing VLDLR-GFP with Nrp1WT or Nrp1 mutants. HA-Nrp1 $\triangle A B$, but not HA-Nrp1 $\triangle A B C$, was coimmunoprecipitated with VLDLR-GFP. *Nonspecific IgG bands. Molecular mass markers $(\mathrm{kDa})$ are shown on the left of the panels. $\boldsymbol{D}$, Co-IP from the lysate of neonatal mouse neocortices. Nrp1 was immunoprecipitated with VLDLR. Molecular mass markers (KDa) are shown on the left of the panels. $\boldsymbol{E}$, Immunostaining of Nrp1 and VLDLR in the developing neocortex. IZ, Intermediate zone. Scale bar, $100 \mu \mathrm{m}$. $\boldsymbol{F}$, Higher-magnification images of the yellow-boxed area in $\boldsymbol{E}$. Arrow indicates the blood vessel. Scale bar, $50 \mu \mathrm{m}$.

superficial-layer neurons was performed (Mizuno et al., 2014). The total length and branching number of apical dendrites in the Nrp1KD neurons were significantly reduced than that of control neurons (Fig. 7Q,R,U,V); however, these abnormalities were rescued by the expression of $\operatorname{Nrp} 1 \mathrm{WT}^{\star}$ (Fig. $7 S, U, V$ ). The shRNA-resistant $\operatorname{Nrp} 1 \Delta \mathrm{a} 2$ mutant $\left(\operatorname{Nrp} 1 \Delta \mathrm{a} 2^{\star}\right)$ that binds to
Reelin-FL, but not to Sema3A, was used to exclude the possibility that Sema3A was involved in this event. The expression of Nrp1 $\Delta \mathrm{a} 2^{*}$ rescued the positional (Fig. $7 J, K$ ) and morphologic (Fig. $7 P, P^{\prime}, T-V$ ) defects of the Nrp1KD neurons. Together, these results provide evidence that the interaction between Reelin-FL and Nrp1 is required for normal apical 

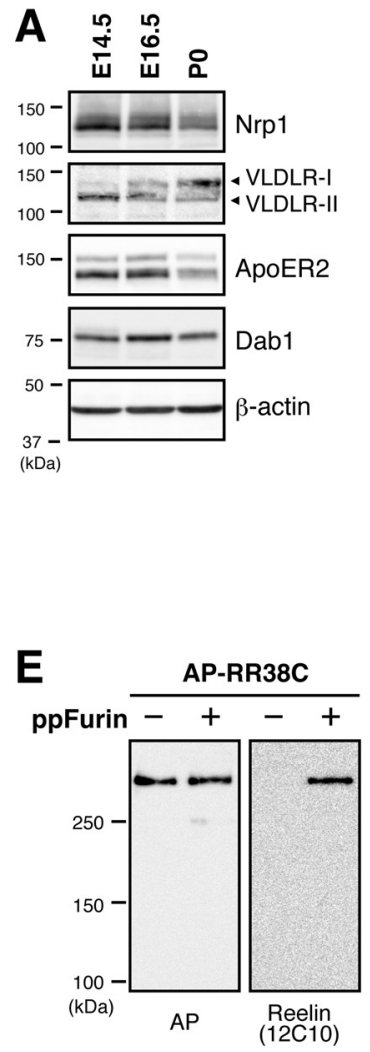

F

$$
\begin{array}{r}
\text { VLDLR-I-GFP }-++ \\
\text { HA-Nrp1 }+-+
\end{array}
$$
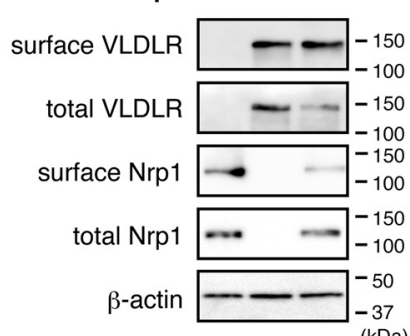

(kDa)

B
AP-RR36

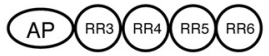

AP-RR38C
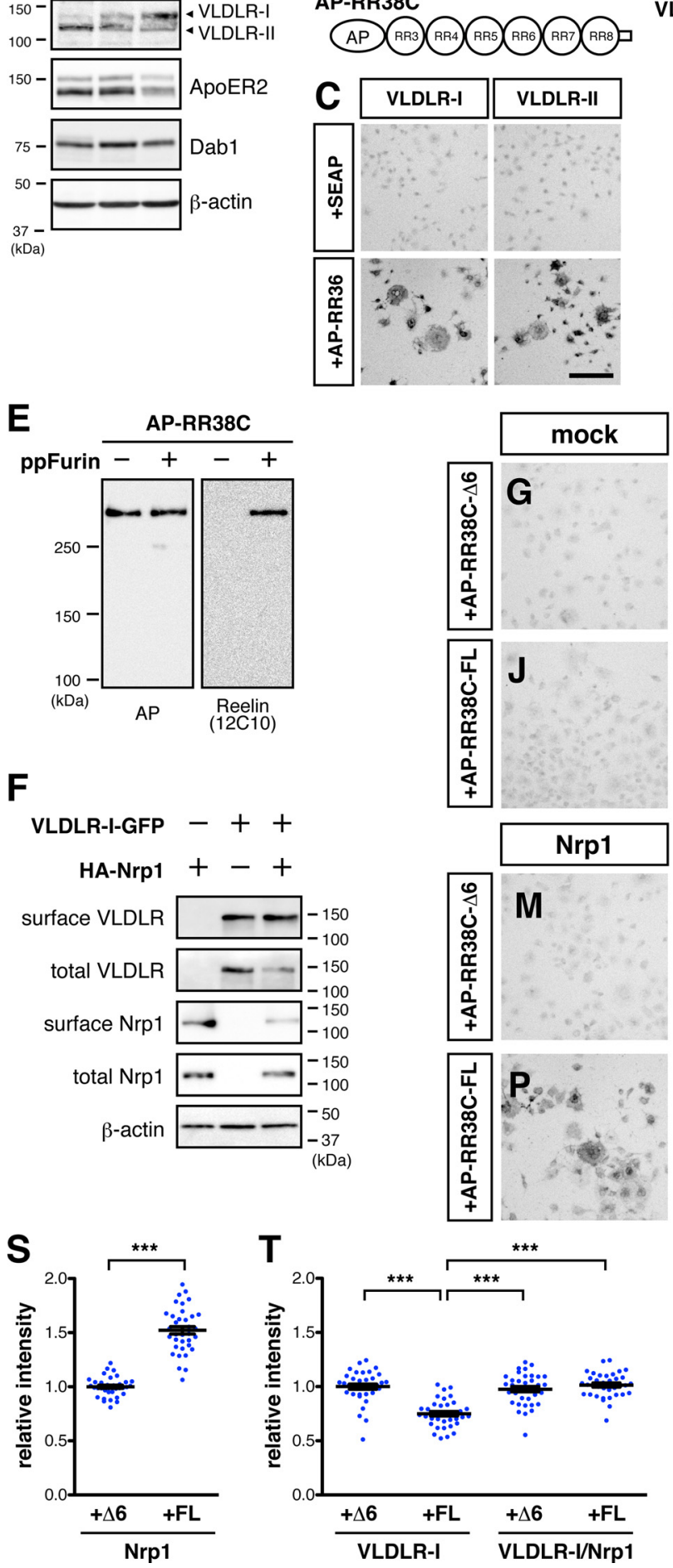
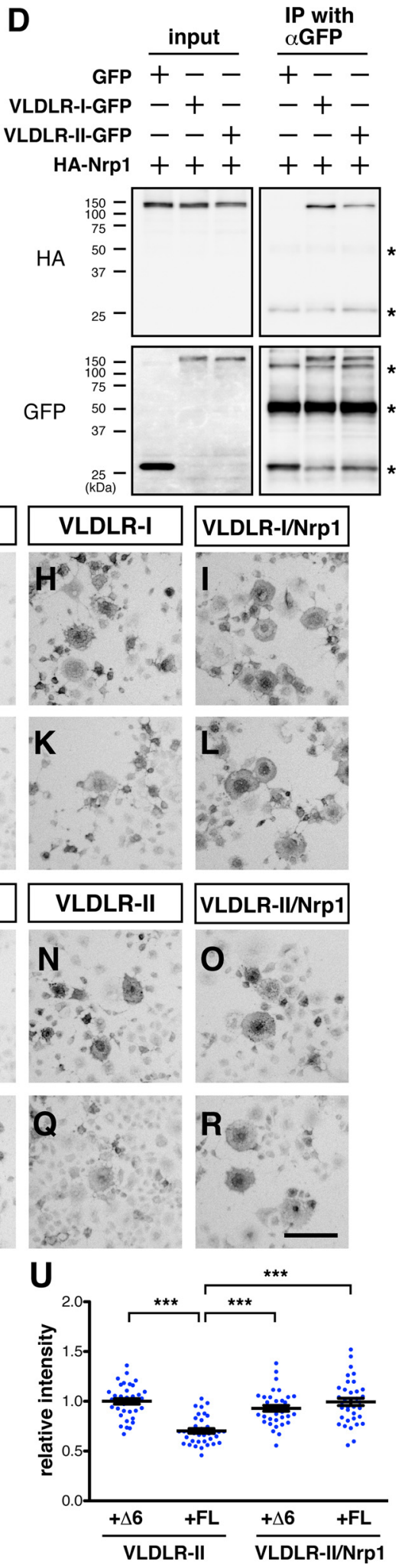

Figure 5. Nrp1 enhances the binding affinity of Reelin-FL to VLDLR. $\boldsymbol{A}$, WB analysis of Nrp1, VLDLR, ApoER2, Dab1, and $\beta$-actin in the neocortices of E14.5, E16.5, and P0 mice. Molecular mass markers $(\mathrm{kDa})$ are shown on the left of the panels. $\boldsymbol{B}$, Schematic diagram of AP-RR36 and AP-RR38C. $\boldsymbol{C}$, AP staining of COS-7 cells. Either secreted AP (SEAP) or AP-RR36 was incubated with COS-7 cells expressing either VLDLR-I or VLDLR-II, and cell surface-bound AP proteins were detected. Scale bar, $200 \mu \mathrm{m}$. D, Co-IP from COS-7 cells expressing HA-Nrp1 with either VLDLRI-GFP or VLDLR-II-GFP. Nrp1 interacts with both VLDLR variants. *Nonspecific lgG bands. Molecular mass markers (kDa) are shown on the left of the panels. $\boldsymbol{E}$, WB analysis of AP-RR38C expressed in HEK293T cells using either anti-AP or anti-intact CTR (12C10) antibodies. The WC cleavage of AP-RR38C was inhibited by the coexpression of ppFurin. Molecular mass markers $(\mathrm{kDa})$ are shown on the left of the panels. $\boldsymbol{F}$, WB analysis of HA-Nrp1 and VLDLR-I-GFP on the surface of COS-7 cells. The expression levels of cell-surface VLDLR-I were approximately identical, regardless of Nrp1. Molecular mass markers $(\mathrm{kDa})$ are shown on the right of the panels. G-R, Assessment of the binding of AP-fused Reelin to COS-7 cells expressing VLDLR and/or Nrp1. APRR38C-FL bound more strongly to VLDLR/Nrp1-expressing cells than to VLDLR-expressing cells. Scale bar, $200 \mu$ m. S, Quantification of the binding of AP-RR38C to COS-7 cells expressing Nrp1. ${ }^{* * *} p<0.001$ (Mann-Whitney $U$ test). $n=36$ cells from three independent experiments. $T$, Quantification of the binding of AP-RR38C to COS-7 cells expressing either VLDLR-I alone or VLDLR- 

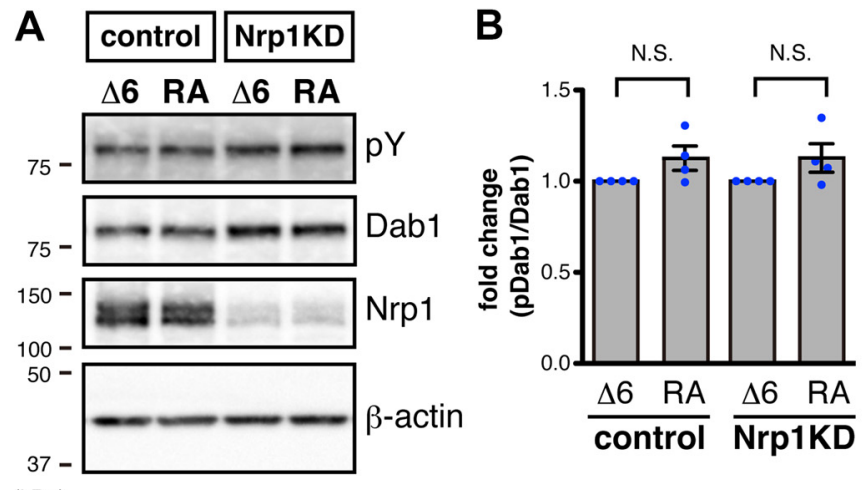

C

$(\mathrm{kDa})$

Figure 6. Nrp1 accelerates the degradation of Dab1 protein in neurons. A, Nrp1KD had little effect on the Dab1 phosphorylation induced by Reelin but increased the expression level of the Dab1 protein in cultured cortical neurons. The cultured cortical neurons were transfected with either the control or the Nrp1KD vector and were then incubated with Reelin- $\Delta 6$ or Reelin-FL. Whole-cell lysates were analyzed by WB using the indicated antibodies. Molecular mass markers $(\mathrm{kDa})$ are shown on the left of the panels. $\boldsymbol{B}$, Quantification of the ratio of phosphorylated Dab1 to total Dab1. Control; $t_{(3)}=1.881, p=0.1566$ (one-sample $t$ test); Nrp1KD; $t_{(3)}=1.634, p=0.2008$ (one-sample $t$ test). $n=4$ experiments. C, Quantification of the ratio of Dab1/ $\beta$-actin. $t_{(3)}=3.787, p=0.0323$ (one-sample $t$ test). $n=4$ experiments. ${ }^{*} p<0.05$.

dendritic development and the positioning of superficial-layer neurons.

Finally, the importance of Nrp1 was confirmed by Reelininduced neuronal aggregation assay (Kubo et al., 2010). The overexpression of Reelin in the VZ caused densely packed neuronal aggregates above the VZ and caused GFP-labeled neurons to extend their leading processes to the cell-sparse central region of the aggregate (Fig. $7 W$ ) (Kubo et al., 2010). When Nrp1 was knocked down, the neuronal aggregates loosened and the leading processes of the GFP-labeled neurons were markedly misoriented (Fig. $7 \mathrm{~W}$ ). These results further support the notion that Nrp1 is an essential component of Reelin-induced dendritic development.

\section{Discussion}

Nrp1 as a receptor for Reelin with an intact CTR

During neural development, the functions of secreted proteins should be appropriately regulated. In the spinal cord, various proteins (e.g., Netrin, Slit, Sonic Hedgehog) control the cell type- and developmental stage-specific axonal responses using different combinations of receptors (Chedotal, 2019). However, the context-specific regulatory mechanisms involved in neocortical development remain largely unknown. Reelin plays pivotal roles in neurogenesis, radial migration, dendritic development, and synapse formation mainly via its canonical receptors, ApoER2 and VLDLR (Santana and Marzolo, 2017). Some coreceptor candidates for Reelin have been proposed (Bock and May, 2016), but there have been no reports of a membrane protein that augments the interaction between Reelin and its canonical receptors (Bock and May, 2016). In this study, we identified Nrp1 as a coreceptor for Reelin and found that the terminal six amino acids (only $0.17 \%$ of the whole Reelin protein) (Kohno et al., 2015) were required for

I and Nrp1. $F_{(3,140)}=31.49$ (one-way ANOVA). ${ }^{* * *} p<0.001$ (Tukey's post hoc test). $n=36$ cells from three independent experiments. $\boldsymbol{U}$, Quantification of the binding of AP-RR38C to COS-7 cells expressing VLDLR-II alone or VLDLR-II and Nrp1. $F_{(3,140)}=22.54$ (one-way ANOVA). ${ }^{* * *} p<0.001$ (Tukey's post hoc test). $n=36$ cells from three independent experiments. the Reelin-Nrp1 interaction. It is surprising that such a tiny difference can contribute to the function of a gigantic protein. Nrp1 is known to be a coreceptor for semaphorins and VEGFs (He and Tessier-Lavigne, 1997; Kolodkin et al., 1997; Soker et al., 1998). The binding properties of Reelin-FL to Nrp1 are similar to those of VEGF-A (Fig. 2E), suggesting that the electronegative surface of the b1 domain (Gelfand et al., 2014) might be involved in the interaction. The binding of Reelin-FL to Nrp1KD neurons was significantly lower than the binding to control neurons but was not fully eliminated (Fig. 3C). It is thus suggested that Reelin-FL can bind to other neuronal proteins in addition to Nrp1. Recently, it was reported that the extracellular Reelin gradient is stabilized by heparan sulfate proteoglycans in the zebrafish tectum (Di Donato et al., 2018). Reelin-FL localizes near the MZ, and seemingly, Reelin-FL does not diffuse well (Jossin et al., 2007; Kohno et al., 2015). The MZ is enriched in chondroitin sulfate proteoglycan (Sheppard et al., 1991); therefore, it is plausible that Reelin-FL binds to some proteoglycans and that this binding controls the localization of Reelin-FL. Nrp1 is a proteoglycan that contains heparan or chondroitin sulfate (Shintani et al., 2006) and is conserved in vertebrates (Bovenkamp et al., 2004). The sequence of the CTR is highly conserved, and the fish CTR also has a putative WC cleavage site (Nakano et al., 2007). These results suggest that proteoglycans, including Nrp1, may be important for the regulation of Reelin functions across species.

\section{Nrp1 locally forms a complex with VLDLR and acts as a coreceptor for Reelin-FL}

Ha et al. (2017) showed that VLDLR, but not ApoER2, contributes to the CTR-dependent signal. VLDLR is highly localized in the apical dendrites of the superficial-layer neurons (Hirota et al., 2015), and VLDLR KO mice show an abnormality of superficial layers that resembles the phenotype of the knock-in mice that lack the CTR of Reelin (Hack et al., 2007; Kohno et al., 2015; Hirota and Nakajima, 2020). Our results indicate that Nrp1 forms a complex with VLDLR (Fig. $4 A-D$ ) and that they are colocalized in the superficial layers (Fig. 4E,F). These results all point to the idea that the CTR-dependent signal via VLDLR/ Nrp1 acts locally in superficial-layer neurons. It is worth noting that VLDLR-I containing an O-linked sugar domain is highly expressed in the postnatal neocortex and is more robustly coimmunoprecipitated with Nrp1 than with VLDLR-II (Fig. 5A,D), raising the possibility that the alternative splicing of VLDLR regulates the responsiveness to Reelin. This point should be investigated in future studies. Importantly, Reelin-FL bound weakly to VLDLR alone but bound strongly to the VLDLR/Nrp1 complex (Fig. $5 G-R$ ), indicating that Nrp1 acts as a coreceptor to augment the binding between Reelin-FL and VLDLR. Moreover, the level of Dab1 protein in Nrp1KD neurons was significantly increased compared with that in control neurons (Fig. 6A). Nrp1 interacts, either directly (Song et al., 2018) or indirectly (Sasaki et al., 2002), with Fyn, which mediates Reelin-dependent Dab1 

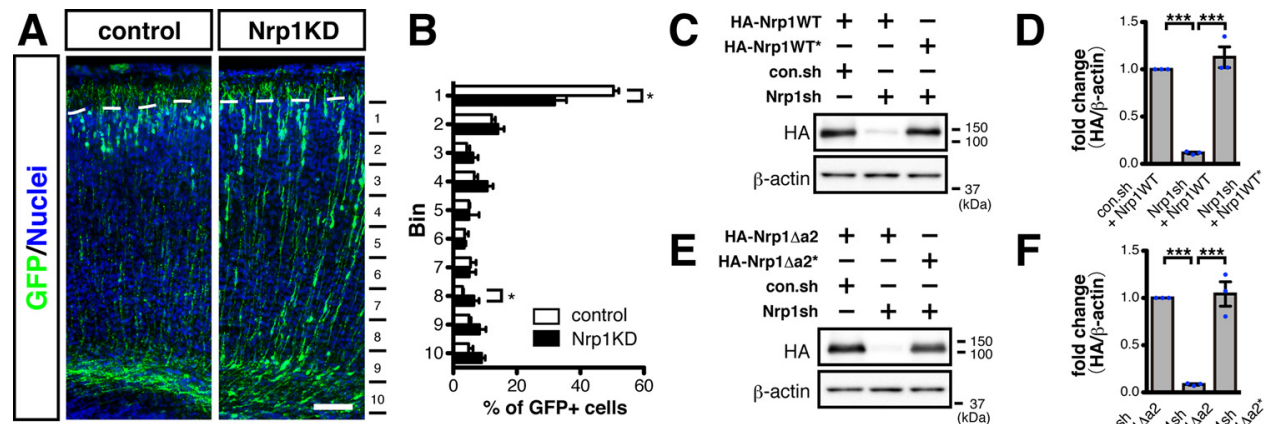

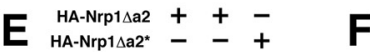 con.sh $+-\overline{-}$

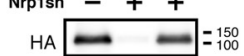 $\beta$-actin $-\square-37$
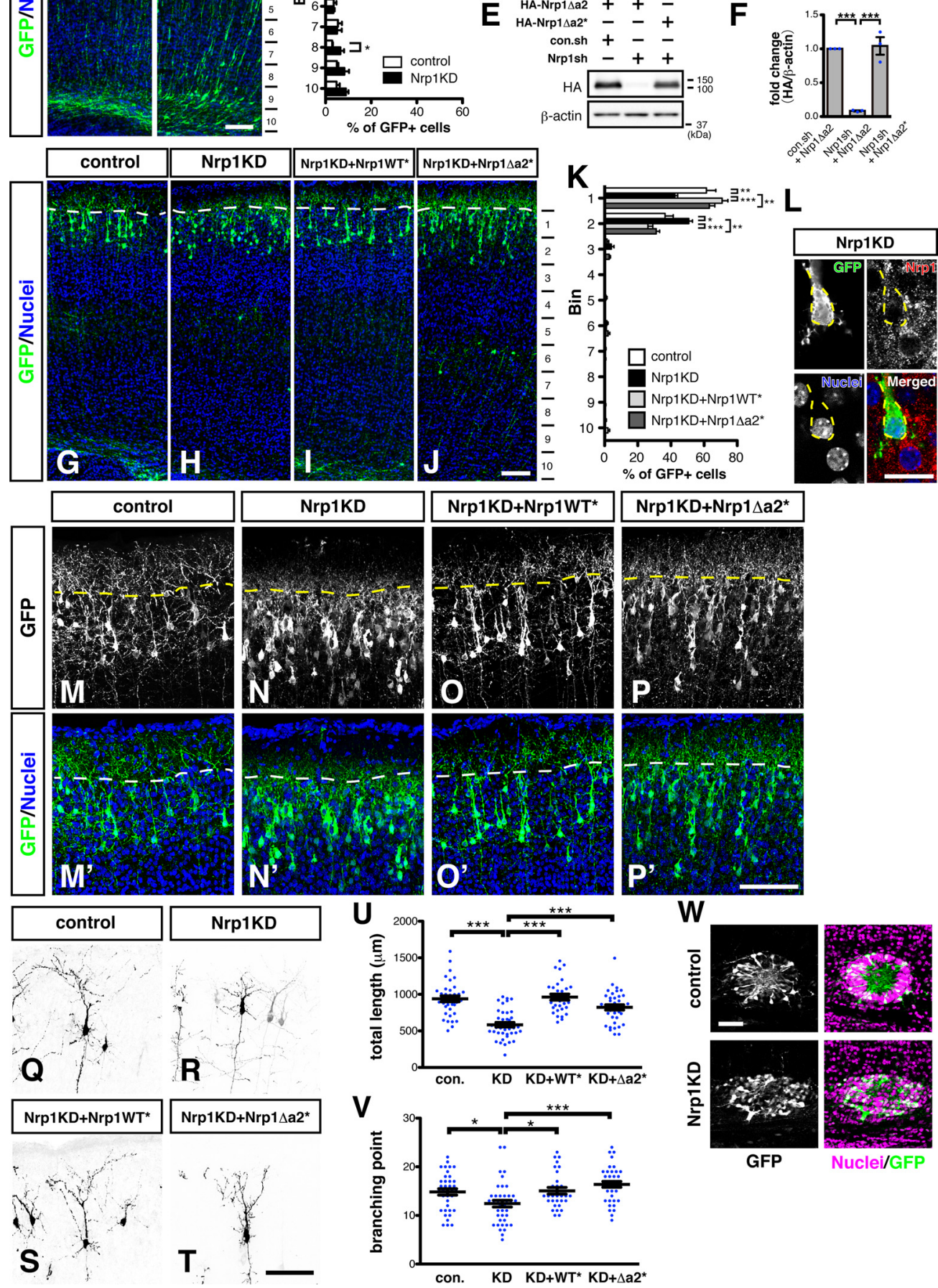

Figure 7. Interaction between Reelin-FL and Nrp1 is required for normal migration and apical dendritic development near the MZ. A, In utero electroporation analysis of Nrp1KD neurons. The indicated plasmids were electroporated with pCAGGS-EGFP at E15.5, and brains were fixed at P1. Brain sections were immunostained using anti-GFP antibodies. Nuclei were stained with Hoechst 33342. Dashed line indicates the border between the MZ and the CP. The neuronal position was impaired in Nrp1KD neurons. Scale bar, $100 \mu \mathrm{m} . B$, Quantification of the neuronal position of GFP-positive cells within the (P. The data were analyzed by Mann-Whitney $U$ test. $n=5$ (control) and 4 brains (Nrp1KD), $p=0.0159$ (BIN1), $p=0.0159$ (BIN8). C, WB analysis of Nrp1WT expressed in COS-7 cells using either anti-HA or anti- $\beta$-actin antibodies. The Nrp1KD vector did not decrease the expression of shRNA-resistant Nrp1WT (Nrp1WT*). Molecular mass markers $(\mathrm{kDa})$ are shown on the right of the panels. $\boldsymbol{D}$, Quantification of the expression level of Nrp1WT. The data were analyzed using a one-way ANOVA $\left(F_{(2,6)}=74.95\right)$ followed by Tukey's post hoc test. $n=3$ experiments. $\boldsymbol{E}, \mathrm{WB}$ analysis of Nrp1 $\Delta \mathrm{a} 2$ expressed in $\operatorname{COS}-7$ cells using either anti-HA or anti- $\beta$-actin antibodies. The Nrp1KD vector did not decrease the expression of shRNA-resistant Nrp1 $\Delta \mathrm{a} 2\left(\operatorname{Nrp} 1 \Delta \mathrm{a} 2^{*}\right)$. Molecular mass markers $(\mathrm{kDa})$ are shown on the right of the panels. $\boldsymbol{F}$, Quantification of the expression levels of Nrp1 $\Delta \mathrm{a} 2$. The data were analyzed by one-way ANOVA $\left(F_{(2,6)}=52.59\right)$ followed by Tukey's post hoc test. $n=3$ experiments. $G-J$, In utero electroporation analysis of Nrp 1KD in superficial-layer neurons. Indicated plasmids were electroporated with pCAGGS-EGFP at E15.5, and brains were fixed at P7. The brain sections were immunostained using anti-GFP antibodies. Nuclei were stained with Hoechst 33342. Neuronal 
phosphorylation (Arnaud et al., 2003). Phosphorylated Dab1 is degraded by the proteasome pathway (Arnaud et al., 2003). These findings suggest that the VLDLR/Nrp1 complex may control the activity of Fyn and the phosphorylation of Dab1.

\section{The role of the Reelin-Nrp1 signal in neocortical development}

Nrp1 regulates the locomotion stage of neuronal migration (Chen et al., 2008). We observed a migration delay in the Nrp1KD neurons, but the extent of the delay was mild compared with a previous study (Chen et al., 2008). This difference may be because of the difference in the KD efficiency. We also found that, at P7, Nrp1KD neurons showed defects in apical dendrite branching, which were completely rescued by the expression of the Nrp1 mutant that binds to Reelin-FL, but not to Sema3A (Fig. $7 N, P$ ). Furthermore, the Reelin-induced neuronal aggregation assay in vivo (Fig. $7 \mathrm{~W}$ ) indicated that the effect of Nrp1KD was very close to that of VLDLR KO (Hirota and Nakajima, 2020) or expression of Reelin- $\Delta 6$ (Kohno et al., 2015), but not to that of ApoER2 KO (Hirota et al., 2018). It was thus indicated that Reelin-FL signaling through Nrp1/VLDLR regulates apical dendrite branching after the neurons reach below the MZ. It was previously reported that Sema3A controls basal dendrite branching in superficial-layer neurons via the Nrp1-TAOK2 signal (de Anda et al., 2012) and controls apical dendrite orientation without affecting its branching (Polleux et al., 2000). Therefore, Nrp1 regulates both the apical and basal dendrite development of neocortical neurons by using different ligands.

The Reelin-VLDLR/ApoER2-Dab1 signal prevents neuronal invasion into the MZ (Herrick and Cooper, 2002; Hack et al., 2007; Kohno et al., 2015; Hirota et al., 2018; Hirota and Nakajima, 2020). Before the cessation of neuronal migration, apical dendrite branching on the neurons in the superficial layers is induced by Reelin (Chai et al., 2015), suggesting that Reelin near the MZ acts as both a "stop" and a "dendrite-branching" signal. We showed that Nrp1KD caused abnormalities in apical dendrite development without the invasion of neurons into the MZ (Fig. $7 N)$. It is therefore suggested that the "stop" and the "dendrite-

$\leftarrow$

position and dendritic development were both impaired in Nrp1KD neurons. Dashed line indicates the border between the MZ and the CP. Scale bar, $100 \mu \mathrm{m}$. $\boldsymbol{K}$, Quantification of the position of GFP-positive cells. Data were analyzed by one-way ANOVA, followed by Tukey's post hoc test. $F_{(3,20)}=11.22$ (BIN1), $F_{(3,20)}=11.55$ (BIN2). ${ }^{*} p<0.05 .{ }^{* *} p<0.01$. ${ }^{* * *} p<0.001 . n=6$ (control), 7 (Nrp1KD), 5 (Nrp1KD+Nrp1WT*), and 6 brains $\left(\right.$ Nrp1KD+Nrp1 $\left.\triangle \mathrm{a} 2^{*}\right)$. L, Immunostaining of Nrp1 in Nrp1KD neurons. The Nrp1KD vector was electroporated with PCAGGS-EGFP at E15.5, and brains were fixed at P7. Brain sections were immunostained using anti-GFP and anti-Nrp1 antibodies. Nuclei were stained with Hoechst 33342. Nrp1KD neurons had decreased Nrp1 immunoreactivity. Yellow dotted line indicates the outer boundary of the GFP-positive Nrp1KD neuron. Scale bar, $20 \mu \mathrm{m} . \mathbf{M}-\mathbf{P}$, Higher-magnification images of the GFP-positive cells near the MZ. Nrp1KD neurons did not extend their apical dendrites to the MZ. This defect was rescued by the expression of either $\mathrm{Nrp}_{1 W T^{*}}$ or Nrp1 $\Delta \mathrm{a}^{*}$. Dashed line indicates the border between the MZ and the CP. Scale bar, $100 \mu \mathrm{m}$. Q-T, Sparse labeling of superficial-layer neurons. The indicated plasmids were electroporated with pCAG-loxP-stop-loxP-mGFP-ires-tTa and TRE-Cre at E15.5, and brains were fixed at P7. Brain sections were immunostained using anti-GFP antibodies. Scale bar, $100 \mu \mathrm{m} . \boldsymbol{U}, \boldsymbol{V}$, Quantification of the apical dendrite length $(\boldsymbol{U})$ and the number of branching points ( $\boldsymbol{V}$ ) of GFP-positive cells. Data were analyzed by one-way ANOVA, followed by Tukey's post hoc test. $F_{(3,141)}=22.72$ (total length), $F_{(3,141)}=6.822$ (branching point). ${ }^{*} p<0.05$. ${ }^{* * *} p<0.001 . n=37$ (control), 40 (Nrp1KD), 30 (Nrp1KD+Nrp1WT*), and 38 neurons $\left(\operatorname{Nrp1KD}+\operatorname{Nrp1} \triangle \mathrm{a} 2^{*}\right)$. W, Nrp1KD in Reelin-induced neuronal aggregates in the neocortex. Expression plasmids of Reelin and EGFP were electroporated with either the control or the Nrp1KD vector at E14.5, and brains were fixed at P1.5. Nrp1 is required for the proper formation of Reelin-induced neuronal aggregates. Scale bar, $50 \mu \mathrm{m}$. branching" signals are regulated by different mechanisms, with the latter involving Reelin-FL signaling through Nrp1. This signal may not only induce Dab1 phosphorylation but also activate a Dab1-independent signaling pathway. Reelin and Sema3A share some common signaling molecules, such as Fyn, Cdk5 (Sasaki et al., 2002), CRMP1 (Yamashita et al., 2006, 2007), and n-cofilin (Aizawa et al., 2001; Chai et al., 2009). These molecules are known to be involved in the regulation of neuronal migration and morphology, suggesting that the Reelin signaling pathway may partially overlap with that of Sema3A.

Nrp1 is expressed in the hippocampus, the olfactory bulb, and the spinal cord (Kawakami et al., 1996). Reelin is also expressed in these tissues (Nakajima et al., 1997; Schiffmann et al., 1997; Yip et al., 2000), suggesting that the Reelin-Nrp1 signal may work in various cells beyond just neocortical neurons. Interestingly, the Reelin signal is required for angiogenesis in the developing neocortex and is closely related to the VEGF signal (Segarra et al., 2018). Nrp1 modulates the VEGF-dependent signal as a coreceptor of VEGF receptor 2 (Pellet-Many et al., 2008). The interaction between Reelin and Nrp1 may also be involved in the regulation of endothelial cell functions.

\section{Reelin-Nrp1 signal and neuropsychiatric disorders}

The hypofunction of Reelin is involved in the onset of neuropsychiatric disorders (Ishii et al., 2016). Furthermore, the loss of CTR-dependent signals induces abnormal behaviors (Sakai et al., 2016). Reelin signaling via Nrp1 thus may be important for brain functions that are impaired in autistic and schizophrenic patients (Moyer et al., 2015; Phillips and Pozzo-Miller, 2015), and its upregulation may help ameliorate the symptoms of these disorders. Further research is required to clarify the significance of ReelinNrp1 signaling in the pathogenesis of neuropsychiatric disorders.

\section{References}

Aizawa H, Wakatsuki S, Ishii A, Moriyama K, Sasaki Y, Ohashi K, SekineAizawa Y, Sehara-Fujisawa A, Mizuno K, Goshima Y, Yahara I (2001) Phosphorylation of cofilin by LIM-kinase is necessary for semaphorin 3A-induced growth cone collapse. Nat Neurosci 4:367-373.

Arnaud L, Ballif BA, Cooper JA (2003) Regulation of protein tyrosine kinase signaling by substrate degradation during brain development. Mol Cell Biol 23:9293-9302.

Bock HH, May P (2016) Canonical and non-canonical Reelin signaling. Front Cell Neurosci 10:166.

Bouche E, Romero-Ortega MI, Henkemeyer M, Catchpole T, Leemhuis J, Frotscher M, May P, Herz J, Bock HH (2013) Reelin induces EphB activation. Cell Res 23:473-490.

Bovenkamp DE, Goishi K, Bahary N, Davidson AJ, Zhou Y, Becker T, Becker CG, Zon LI, Klagsbrun M (2004) Expression and mapping of duplicate neuropilin-1 and neuropilin-2 genes in developing zebrafish. Gene Expr Patterns 4:361-370.

Chai X, Frotscher M (2016) How does Reelin signaling regulate the neuronal cytoskeleton during migration? Neurogenesis 3:e1242455.

Chai X, Förster E, Zhao S, Bock HH, Frotscher M (2009) Reelin stabilizes the actin cytoskeleton of neuronal processes by inducing $n$-cofilin phosphorylation at serine3. J Neurosci 29:288-299.

Chai X, Fan L, Shao H, Lu X, Zhang W, Li J, Wang J, Chen S, Frotscher M, Zhao S (2015) Reelin induces branching of neurons and radial glial cells during corticogenesis. Cereb Cortex 25:3640-3653.

Chedotal A (2019) Roles of axon guidance molecules in neuronal wiring in the developing spinal cord. Nat Rev Neurosci 20:380-396.

Chen G, Sima J, Jin M, Wang KY, Xue XJ, Zheng W, Ding YQ, Yuan XB (2008) Semaphorin-3A guides radial migration of cortical neurons during development. Nat Neurosci 11:36-44.

Cooper JA (2014) Molecules and mechanisms that regulate multipolar migration in the intermediate zone. Front Cell Neurosci 8:386. 
D’Arcangelo G, Nakajima K, Miyata T, Ogawa M, Mikoshiba K, Curran T (1997) Reelin is a secreted glycoprotein recognized by the CR-50 monoclonal antibody. J Neurosci 17:23-31.

de Anda FC, Rosario AL, Durak O, Tran T, Graff J, Meletis K, Rei D, Soda T, Madabhushi R, Ginty DD, Kolodkin AL, Tsai LH (2012) Autism spectrum disorder susceptibility gene TAOK2 affects basal dendrite formation in the neocortex. Nat Neurosci 15:1022-1031.

Di Donato V, De Santis F, Albadri S, Auer TO, Duroure K, Charpentier M, Concordet JP, Gebhardt C, Del Bene F (2018) An attractive Reelin gradient establishes synaptic lamination in the vertebrate visual system. Neuron 97:1049-1062.e1046.

Gelfand MV, Hagan N, Tata A, Oh WJ, Lacoste B, Kang KT, Kopycinska J, Bischoff J, Wang JH, Gu C (2014) Neuropilin-1 functions as a VEGFR2 coreceptor to guide developmental angiogenesis independent of ligand binding. eLife 3:e03720.

Gonda Y, Andrews WD, Tabata H, Namba T, Parnavelas JG, Nakajima K, Kohsaka S, Hanashima C, Uchino S (2013) Robol regulates the migration and laminar distribution of upper-layer pyramidal neurons of the cerebral cortex. Cereb Cortex 23:1495-1508.

Gu C, Limberg BJ, Whitaker GB, Perman B, Leahy DJ, Rosenbaum JS, Ginty DD, Kolodkin AL (2002) Characterization of neuropilin-1 structural features that confer binding to semaphorin $3 \mathrm{~A}$ and vascular endothelial growth factor 165. J Biol Chem 277:18069-18076.

Ha S, Tripathi PP, Mihalas AB, Hevner RF, Beier DR (2017) C-terminal region truncation of RELN disrupts an interaction with VLDLR, causing abnormal development of the cerebral cortex and hippocampus. J Neurosci 37:960-971.

Hack I, Hellwig S, Junghans D, Brunne B, Bock HH, Zhao S, Frotscher M (2007) Divergent roles of ApoER2 and Vldlr in the migration of cortical neurons. Development 134:3883-3891.

He Z, Tessier-Lavigne M (1997) Neuropilin is a receptor for the axonal chemorepellent Semaphorin III. Cell 90:739-751.

Herrick TM, Cooper JA (2002) A hypomorphic allele of Dab1 reveals regional differences in Reelin-Dab1 signaling during brain development. Development 129:787-796.

Hibi T, Mizutani M, Baba A, Hattori M (2009) Splicing variations in the ligand-binding domain of ApoER2 results in functional differences in the binding properties to Reelin. Neurosci Res 63:251-258.

Hirota Y, Nakajima K (2017) Control of neuronal migration and aggregation by Reelin signaling in the developing cerebral cortex. Front Cell Dev Biol 5:40.

Hirota Y, Nakajima K (2020) VLDLR is not essential for Reelin-induced neuronal aggregation but suppresses neuronal invasion into the marginal zone. Development 147:dev189936.

Hirota Y, Kubo K, Katayama K, Honda T, Fujino T, Yamamoto TT, Nakajima K (2015) Reelin receptors ApoER2 and VLDLR are expressed in distinct spatiotemporal patterns in developing mouse cerebral cortex. J Comp Neurol 523:463-478.

Hirota Y, Kubo KI, Fujino T, Yamamoto TT, Nakajima K (2018) ApoER2 controls not only neuronal migration in the intermediate zone but also termination of migration in the developing cerebral cortex. Cereb Cortex 28:223-235

Hoe HS, Lee KJ, Carney RS, Lee J, Markova A, Lee JY, Howell BW, Hyman BT, Pak DT, Bu G, Rebeck GW (2009) Interaction of Reelin with amyloid precursor protein promotes neurite outgrowth. J Neurosci 29:7459-7473.

Hong TM, Chen YL, Wu YY, Yuan A, Chao YC, Chung YC, Wu MH, Yang SC, Pan SH, Shih JY, Chan WK, Yang PC (2007) Targeting neuropilin 1 as an antitumor strategy in lung cancer. Clin Cancer Res 13:4759-4768.

Ishii K, Kubo KI, Nakajima K (2016) Reelin and neuropsychiatric disorders. Front Cell Neurosci 10:229.

Jossin Y, Goffinet AM (2007) Reelin signals through phosphatidylinositol 3kinase and Akt to control cortical development and through mTor to regulate dendritic growth. Mol Cell Biol 27:7113-7124.

Jossin Y, Gui L, Goffinet AM (2007) Processing of Reelin by embryonic neurons is important for function in tissue but not in dissociated cultured neurons. J Neurosci 27:4243-4252.

Kanatani S, Honda T, Aramaki M, Hayashi K, Kubo K, Ishida M, Tanaka DH, Kawauchi T, Sekine K, Kusuzawa S, Kawasaki T, Hirata T, Tabata H, Uhlen P, Nakajima K (2015) The COUP-TFII/Neuropilin-2 is a molecular switch steering diencephalon-derived GABAergic neurons in the developing mouse brain. Proc Natl Acad Sci USA 112:E4985-E4994.
Kawakami A, Kitsukawa T, Takagi S, Fujisawa H (1996) Developmentally regulated expression of a cell surface protein, neuropilin, in the mouse nervous system. J Neurobiol 29:1-17.

Kohno T, Honda T, Kubo K, Nakano Y, Tsuchiya A, Murakami T, Banno H, Nakajima K, Hattori M (2015) Importance of Reelin C-terminal region in the development and maintenance of the postnatal cerebral cortex and its regulation by specific proteolysis. J Neurosci 35:4776-4787.

Kolodkin AL, Levengood DV, Rowe EG, Tai YT, Giger RJ, Ginty DD (1997) Neuropilin is a semaphorin III receptor. Cell 90:753-762.

Kubo K, Honda T, Tomita K, Sekine K, Ishii K, Uto A, Kobayashi K, Tabata H, Nakajima K (2010) Ectopic Reelin induces neuronal aggregation with a normal birthdate-dependent "inside-out" alignment in the developing neocortex. J Neurosci 30:10953-10966.

Matsuda T, Cepko CL (2007) Controlled expression of transgenes introduced by in vivo electroporation. Proc Natl Acad Sci USA 104:1027-1032.

Matsuki T, Matthews RT, Cooper JA, van der Brug MP, Cookson MR, Hardy JA, Olson EC, Howell BW (2010) Reelin and stk25 have opposing roles in neuronal polarization and dendritic Golgi deployment. Cell 143:826836.

Mizuno H, Luo W, Tarusawa E, Saito YM, Sato T, Yoshimura Y, Itohara S, Iwasato T (2014) NMDAR-regulated dynamics of layer 4 neuronal dendrites during thalamocortical reorganization in neonates. Neuron $82: 365-379$.

Mizushima S, Nagata S (1990) pEF-BOS, a powerful mammalian expression vector. Nucleic Acids Res 18:5322.

Moyer CE, Shelton MA, Sweet RA (2015) Dendritic spine alterations in schizophrenia. Neurosci Lett 601:46-53.

Nadarajah B, Brunstrom JE, Grutzendler J, Wong RO, Pearlman AL (2001) Two modes of radial migration in early development of the cerebral cortex. Nat Neurosci 4:143-150.

Nakajima K, Mikoshiba K, Miyata T, Kudo C, Ogawa M (1997) Disruption of hippocampal development in vivo by CR-50 mAb against Reelin. Proc Natl Acad Sci USA 94:8196-8201.

Nakano Y, Kohno T, Hibi T, Kohno S, Baba A, Mikoshiba K, Nakajima K, Hattori M (2007) The extremely conserved C-terminal region of Reelin is not necessary for secretion but is required for efficient activation of downstream signaling. J Biol Chem 282:20544-20552.

Niu S, Renfro A, Quattrocchi CC, Sheldon M, D’Arcangelo G (2004) Reelin promotes hippocampal dendrite development through the VLDLR/ ApoER2-Dab1 pathway. Neuron 41:71-84.

Niwa H, Yamamura K, Miyazaki J (1991) Efficient selection for high-expression transfectants with a novel eukaryotic vector. Gene 108:193-199.

Noctor SC, Martinez-Cerdeno V, Ivic L, Kriegstein AR (2004) Cortical neurons arise in symmetric and asymmetric division zones and migrate through specific phases. Nat Neurosci 7:136-144.

O’Dell RS, Cameron DA, Zipfel WR, Olson EC (2015) Reelin prevents apical neurite retraction during terminal translocation and dendrite initiation. J Neurosci 35:10659-10674.

Onoue A, Takeuchi M, Kohno T, Hattori M (2014) Aberrant fragment of Dab1 protein is present in yotari mouse. Neurosci Res 88:23-27.

Pellet-Many C, Frankel P, Jia H, Zachary I (2008) Neuropilins: structure, function and role in disease. Biochem J 411:211-226.

Phillips M, Pozzo-Miller L (2015) Dendritic spine dysgenesis in autism related disorders. Neurosci Lett 601:30-40.

Polleux F, Morrow T, Ghosh A (2000) Semaphorin 3A is a chemoattractant for cortical apical dendrites. Nature 404:567-573.

Sakai K, Shoji H, Kohno T, Miyakawa T, Hattori M (2016) Mice that lack the C-terminal region of Reelin exhibit behavioral abnormalities related to neuropsychiatric disorders. Sci Rep 6:28636.

Sakai K, Tiebel O, Ljungberg MC, Sullivan M, Lee HJ, Terashima T, Li R, Kobayashi K, Lu HC, Chan L, Oka K (2009) A neuronal VLDLR variant lacking the third complement-type repeat exhibits high capacity binding of apoE containing lipoproteins. Brain Res 1276:11-21.

Santana J, Marzolo MP (2017) The functions of Reelin in membrane trafficking and cytoskeletal dynamics: implications for neuronal migration, polarization and differentiation. Biochem J 474:3137-3165.

Sasaki Y, Cheng C, Uchida Y, Nakajima O, Ohshima T, Yagi T, Taniguchi M, Nakayama T, Kishida R, Kudo Y, Ohno S, Nakamura F, Goshima Y (2002) Fyn and Cdk5 mediate semaphorin-3A signaling, which is involved in regulation of dendrite orientation in cerebral cortex. Neuron 35:907-920. 
Schiffmann SN, Bernier B, Goffinet AM (1997) Reelin mRNA expression during mouse brain development. Eur J Neurosci 9:1055-1071.

Segarra M, Aburto MR, Cop F, Llao-Cid C, Hartl R, Damm M, Bethani I, Parrilla M, Husainie D, Schanzer A, Schlierbach H, Acker T, Mohr L, Torres-Masjoan L, Ritter M, Acker-Palmer A (2018) Endothelial Dab1 signaling orchestrates neuro-glia-vessel communication in the central nervous system. Science 361:eaao2861.

Sekine K, Honda T, Kawauchi T, Kubo K, Nakajima K (2011) The outermost region of the developing cortical plate is crucial for both the switch of the radial migration mode and the Dab1-dependent "inside-out" lamination in the neocortex. J Neurosci 31:9426-9439.

Senturk A, Pfennig S, Weiss A, Burk K, Acker-Palmer A (2011) Ephrin Bs are essential components of the Reelin pathway to regulate neuronal migration. Nature 472:356-360.

Shintani Y, Takashima S, Asano Y, Kato H, Liao Y, Yamazaki S, Tsukamoto O, Seguchi O, Yamamoto H, Fukushima T, Sugahara K, Kitakaze M, Hori M (2006) Glycosaminoglycan modification of neuropilin-1 modulates VEGFR2 signaling. EMBO J 25:3045-3055.

Sheppard AM, Hamilton SK, Pearlman AL (1991) Changes in the distribution of extracellular matrix components accompany early morphogenetic events of mammalian cortical development. J Neurosci 11:3928-3942.

Soker S, Takashima S, Miao HQ, Neufeld G, Klagsbrun M (1998) Neuropilin-1 is expressed by endothelial and tumor cells as an isoformspecific receptor for vascular endothelial growth factor. Cell 92:735-745.

Song Y, Cao P, Gu Z, Xiao J, Lian M, Huang D, Xing J, Zhang Y, Feng X, Wang C (2018) The role of neuropilin-1-FYN interaction in odontoblast differentiation of dental pulp stem cells. Cell Reprogram 20:117-126.

Suto F, Ito K, Uemura M, Shimizu M, Shinkawa Y, Sanbo M, Shinoda T, Tsuboi M, Takashima S, Yagi T, Fujisawa H (2005) Plexin-a4 mediates axon-repulsive activities of both secreted and transmembrane semaphorins and plays roles in nerve fiber guidance. J Neurosci 25:3628-3637.

Tabata H, Nakajima K (2001) Efficient in utero gene transfer system to the developing mouse brain using electroporation: visualization of neuronal migration in the developing cortex. Neuroscience 103:865-872.
Tabata H, Nakajima K (2003) Multipolar migration: the third mode of radial neuronal migration in the developing cerebral cortex. J Neurosci 23:9996-10001.

Tabata H, Nakajima K (2008) Labeling embryonic mouse central nervous system cells by in utero electroporation. Dev Growth Differ 50:507-511.

Tabata H, Kanatani S, Nakajima K (2009) Differences of migratory behavior between direct progeny of apical progenitors and basal progenitors in the developing cerebral cortex. Cereb Cortex 19:2092-2105.

Uchida T, Baba A, Perez-Martinez FJ, Hibi T, Miyata T, Luque JM, Nakajima K, Hattori M (2009) Downregulation of functional Reelin receptors in projection neurons implies that primary Reelin action occurs at early/ premigratory stages. J Neurosci 29:10653-10662.

Valnegri P, Puram SV, Bonni A (2015) Regulation of dendrite morphogenesis by extrinsic cues. Trends Neurosci 38:439-447.

Wasser CR, Herz J (2017) Reelin: neurodevelopmental architect and homeostatic regulator of excitatory synapses. J Biol Chem 292:1330-1338.

Yamashita N, Uchida Y, Ohshima T, Hirai S, Nakamura F, Taniguchi M, Mikoshiba K, Honnorat J, Kolattukudy P, Thomasset N, Takei K, Takahashi T, Goshima Y (2006) Collapsin response mediator protein 1 mediates Reelin signaling in cortical neuronal migration. J Neurosci 26:13357-13362.

Yamashita N, Morita A, Uchida Y, Nakamura F, Usui H, Ohshima T, Taniguchi M, Honnorat J, Thomasset N, Takei K, Takahashi T, Kolattukudy P, Goshima Y (2007) Regulation of spine development by semaphorin3A through cyclin-dependent kinase 5 phosphorylation of collapsin response mediator protein 1. J Neurosci 27:12546-12554.

Yip JW, Yip YP, Nakajima K, Capriotti C (2000) Reelin controls position of autonomic neurons in the spinal cord. Proc Natl Acad Sci USA 97:86128616.

Yoshida M, Assimacopoulos S, Jones KR, Grove EA (2006) Massive loss of Cajal-Retzius cells does not disrupt neocortical layer order. Development 133:537-545.

Zhong M, Munzer JS, Basak A, Benjannet S, Mowla SJ, Decroly E, Chretien M, Seidah NG (1999) The prosegments of furin and PC7 as potent inhibitors of proprotein convertases: in vitro and ex vivo assessment of their efficacy and selectivity. J Biol Chem 274:33913-33920. 